Bundesgesundheitsbl 2018 $\cdot 61: 1034-1051$ https://doi.org/10.1007/s00103-018-2761-8 (c) Springer-Verlag GmbH Deutschland, ein Teil von Springer Nature 2018

\author{
Stephan Ehl' · Christian Bogdan 2,3 Tim Niehues $^{4}$ - Gerd Burchard ${ }^{3,5}$. \\ Ulrich Baumann ${ }^{6}$. Jane Hecht ${ }^{7}$. Judith Koch ${ }^{7}$. Jennifer Neubert ${ }^{8}$. \\ Miriam Wiese-Posselt ${ }^{7} \cdot$ Fred Zepp $^{3,9}$ \\ ${ }^{1}$ Centrum für Chronische Immundefizienz (CCI), Universitätsklinikum Freiburg, Freiburg, Deutschland \\ ${ }^{2}$ Mikrobiologisches Institut - Klinische Mikrobiologie, Immunologie und Hygiene Universitätsklinikum \\ Erlangen und Friedrich-Alexander-Universität (FAU) Erlangen-Nürnberg, Erlangen, Deutschland \\ ${ }^{3}$ Ständige Impfkommission am Robert Koch-Institut Berlin, Berlin, Deutschland \\ ${ }^{4}$ Zentrum für Kinder- und Jugendmedizin Helios Klinikum Krefeld, Krefeld, Deutschland \\ ${ }^{5}$ Bernhard-Nocht-Institut für Tropenmedizin, Hamburg, Deutschland \\ ${ }^{6}$ Pädiatrische Pneumologie, Allergologie und Neonatologie, Medizinische Hochschule Hannover, Hannover, \\ Deutschland \\ ${ }^{7}$ Abteilung für Infektionsepidemiologie, Fachgebiet Impfprävention, Robert Koch-Institut Berlin, Berlin, \\ Deutschland \\ ${ }^{8}$ Klinik für Kinder-Onkologie, -Hämatologie und Klinische Immunologie, Universitätsklinikum Düsseldorf, \\ Düsseldorf, Deutschland \\ ${ }^{9}$ Zentrum für Kinder- und Jugendmedizin, Universitätsmedizin Mainz, Mainz, Deutschland
}

\title{
Impfen bei Immundefizienz
}

\section{Anwendungshinweise zu den von der Ständigen Impfkommission empfohlenen Impfungen. (II) Impfen bei 1. Primären Immundefekt- erkrankungen und 2. HIV-Infektion}

\section{Disclaimer}

Auf Initiative der Ständigen Impfkommission (STIKO) hat eine Arbeitsgruppe aus Experten der zuständigen Fachgesellschaften, Mitarbeitern des Robert Koch-Instituts und STIKO-Mitgliedern die hier vorliegenden Anwendungshinweise für das Impfen bei 1. primären Immundefekterkrankungen und 2. HIV-Infektion erarbeitet. Das methodische Vorgehen wurde im Grundlagenpapier „Impfen bei Immundefizienz" beschrieben (siehe: https://link.springer.com/content/ pdf/10.1007\%2Fs00103-017-2555-4.pdf).

Diese Anwendungshinweise sind keine STIKO-Empfehlungen nach $\$ 20$ Abs. 2 IfSG und haben damit keine leistungsrechtlichen Implikationen. Diese Anwendungshinweise sollen als Hilfestellung für die Ärztinnen und Ärzte zu Impfungen bei Patientinnen und Patienten mit Immundefizienz dienen. In den jeweiligen Abschnitten wird auf bestehende Emp- fehlungen der STIKO Bezug genommen. Anwendungshinweise, die von den aktuell gültigen Empfehlungen der STIKO (Epidemiologisches Bulletin 34/2017) abweichen, sind im folgenden Dokument rot gekennzeichnet. Die STIKO prüft aktuell, ob ihre Empfehlungen nach $\$ 20$ Abs. 2 IfSG auf der Grundlage der Anwendungshinweise entsprechend angepasst bzw. erweitert werden sollten. Bitte beachten Sie, dass nur solche Impfempfehlungen der STIKO regelhaft zu Lasten der GKV erbracht werden können, die in die Schutzimpfungs-Richtlinie des Gemeinsamen Bundesausschusses übernommen wurden. Der Gemeinsame Bundesausschuss bestimmt gemäß $₫ 20$ i Abs. 1 Satz 3 SGB V Einzelheiten zu Art und Umfang der Leistungen für Schutzimpfungen in seiner Schutzimpfungs-Richtlinie auf der Grundlage der Empfehlungen nach $\$ 20$ Abs. 2 IfSG. In allen anderen Fällen sollte die Kostenübernahme zuvor mit der jeweiligen Krankenkasse geklärt werden. 


\section{Impfen bei Primären Immundefekterkrankungen (inkl. autoinflammatorischer Erkrankungen)}

\begin{tabular}{|c|c|c|}
\hline \multicolumn{3}{|c|}{ Inhalt } \\
\hline 1 & \multicolumn{2}{|c|}{ Einleitung } \\
\hline 2 & \multirow{2}{*}{\multicolumn{2}{|c|}{$\begin{array}{l}\text { Allgemeine Hir } \\
\text { PID Patienten }\end{array}$}} \\
\hline & & Patienten \\
\hline & \multicolumn{2}{|c|}{2.1 Totimpfstoffe } \\
\hline & & 2.1.1 Diagnostische Impfungen \\
\hline & 2.2 & Lebendimpfstoffe \\
\hline & 2.3 & $\begin{array}{l}\text { Vorgehen bei Einzelfallentscheidun- } \\
\text { gen }\end{array}$ \\
\hline & 2.4 & $\begin{array}{l}\text { Impfungen unter dauerhafter } \\
\text { Immunglobulin-Ersatztherapie }\end{array}$ \\
\hline & 2.5 & Impfungen bei PID-Patienten vor \\
\hline & & Stammzelltransplantation \\
\hline 3 & \multirow{2}{*}{\multicolumn{2}{|c|}{$\begin{array}{l}\text { Spezifische Hinweise zum Impfen bei } \\
\text { anqeborenen Immundefekten }\end{array}$}} \\
\hline & & \\
\hline & 3.1 & Kombinierte Immundefekte \\
\hline & & $\begin{array}{l}\text { Kombinierte Immundefekte mit } \\
\text { syndromalen Erscheinungen }\end{array}$ \\
\hline & \multirow[t]{2}{*}{3.3} & Erkrankungen mit überwiegendem \\
\hline & & Antikörpermangel \\
\hline & 3.4 & Erkrankungen aufgrund einer \\
\hline & & $7 a h$ \\
\hline & 3.5 & $\begin{array}{l}\text { Detekte der Lah } \\
\text { Phagozyten }\end{array}$ \\
\hline & \multirow[t]{3}{*}{3.6} & Defekte der Pathogenerkennung, \\
\hline & & der Zytokinproduktion oder der \\
\hline & & Zytokinsignaltransduktion \\
\hline & 3.7 & Autoinflammatorische Erkrankungen \\
\hline & 3.8 & Komplementdefekte \\
\hline \multirow[t]{2}{*}{4} & \multicolumn{2}{|c|}{ Impfen von Kontaktpersonen und } \\
\hline & \multicolumn{2}{|c|}{ Postexpositionsprophylaxe } \\
\hline \multirow[t]{4}{*}{5} & \multicolumn{2}{|c|}{ Hinweise zu Reiseimpfungen } \\
\hline & 5.1 & Gelbfieber \\
\hline & 5.2 & Typhus, Cholera \\
\hline & 5.3 & Tollwut \\
\hline
\end{tabular}

\section{Einleitung}

Infektionen sind eine wesentliche Ursache von Morbidität und Mortalität bei Patienten mit primären (d.h. angeborenen) Immundefekten („primary immunodeficiencies“, PID). Der Einsatz prophylaktischer Maßnahmen einschließlich Impfungen, Immunglobulinen und antimikrobieller Langzeittherapie ist daher in vielen Fällen sinnvoll und notwendig [1]. Aus der je nach Immundefekt vorliegenden Störung des Immunsystems ergeben sich einerseits Risiken für verschiedene Infektionen, andererseits eine unterschiedlich beeinträchtigte Fähigkeit zum Aufbau eines Impfschutzes sowie gegebenenfalls eine Gefährdung durch Lebendimpfungen [2,
3]. Daher sind allgemein gültige Empfehlungen für Impfungen von PID-Patienten nicht möglich. Vielmehr ist es unerlässlich, sich mit der Art des Immundefekts genau auseinanderzusetzen, um Nutzen und Risiken im Einzelfall abzuwägen $[4,5]$.

Angeborene Immundefekte lassen sich je nach den betroffenen Komponenten des Immunsystems verschiedenen Gruppen zuordnen. Die nachfolgenden Anwendungshinweise zu Impfungen bei Patienten mit PID folgen der Klassifikation der Immundefekte durch die „International Union of Immunological Societies“ (IUIS) [6]. Aufgrund der enormen Anzahl molekular definierter Erkrankungen (>300) kann im Folgenden nur auf die häufigeren Immundefekte eingegangen werden.

\section{Allgemeine Hinweise für die Impfung von PID Patienten}

\subsection{Totimpfstoffe}

Die Verabreichung der von der STIKO empfohlenen Standard- und Indikationsimpfungen mit Totimpfstoffen ist ohne zusätzliche Risiken möglich. Ob durch die Impfung eine protektive Immunantwort aufgebaut werden kann, ist allerdings abhängig von der Art der Funktionsstörung des Immunsystems.

\subsubsection{Diagnostische Impfungen}

Zur Abschätzung der Auswirkungen eines Immundefektes auf die Impfantwort können diagnostische Impfungen mit Totimpfstoffen vorgenommen werden. Weitere Informationen dazu sind im Grundlagenpapier aufgeführt [3].

\subsection{Lebendimpfstoffe}

Bei vielen, aber nicht allen Patienten mit Immundefizienz sind Lebendimpfungen kontraindiziert. Für manche Erkrankungsgruppen können klare Indikationen oder Kontraindikationen ausgesprochen werden, bei anderen Erkrankungen wird zur Einzelfallentscheidung geraten. Wenn auf Basis einer Nutzen-Risiko-Abwägung in diesen Fällen ein Lebendimpfstoff verabreicht wird, handelt es sich im Regelfall um einen „Off-label-Gebrauch“ (Off-label-use). Dementsprechend ist die vorherige umfassende Aufklärung und
Beratung des Patienten bzw. seiner Sorgeberechtigten über Nutzen und Risiken der Impfung und die geplante Off-labelAnwendung unabdingbar. Weiterhin sollte die Einwilligung idealerweise durch die Unterschrift des Patienten bzw. seines Sorgeberechtigten bestätigt werden. Weiterhin müssen die ärztliche Aufklärung und Behandlung in der Patientenakte umfassend dokumentiert werden.

Unterstützende Erläuterungen zu Lebendimpfungen bei Patienten mit PID sind in den folgenden Unterkapiteln aufgeführt.

\subsection{Vorgehen bei \\ Einzelfallentscheidungen}

Aufgrund der Heterogenität angeborener Immundefekte und ihrer individuellen Ausprägung ist in vielen Fällen bei vorliegender Impfindikation eine Einzelfallentscheidung notwendig. Dies betrifft insbesondere die Verabreichung von Lebendimpfungen. Es gibt keine validierten Messgrößen, mit denen die Restfunktion des Immunsystems und damit die Unbedenklichkeit von Lebendimpfstoffen vorhergesagt werden kann. Daher müssen bei solchen Einzelfallentscheidungen neben der Grundkrankheit die vorliegenden immunologischen Untersuchungsbefunde (z. B. Impfantikörper nach [diagnostischer] Impfung, Ergebnisse der T-Zell-Proliferationsassays) und der klinische Verlauf beim Patienten und ggf. auch bei betroffenen Familienmitgliedern berücksichtigt werden. Auf dieser Basis sollte durch einen in der Behandlung von Immundefekterkrankungen erfahrenen Arzt eine Nutzen-Risiko-Abwägung erfolgen.

Eine Liste mit Kontaktadressen des Netzwerks für angeborene Immundefekte findet sich unter http://www.find-id.net.

\subsection{Impfungen unter dauerhafter Immunglobulin-Ersatztherapie}

Eine Impfung kann auch unter Immunglobulin-Ersatztherapie sinnvoll sein, wenn eine protektive T-Zell-Antwort zu erwarten oder wenn eine Restimmunfunktion vorhanden ist, die eine Antikörper-Antwort auf die Impfung wahrscheinlich macht. 
Es gibt nur wenige Daten zur Wirksamkeit von Impfungen unter Immunglobulin-Ersatztherapie. Bei einzelnen Patienten mit „common variable immunodeficiency" (CVID) (s. Abschn. 3.3) konnte auch unter Substitutionstherapie eine Antikörper-Antwort gegen verschiedene Impfstoffe einschließlich Influenza nachgewiesen werden [7]. Ob diese Antikörper-Antwort den Infektionsschutz über den durch die zugeführten Immunglobuline vermittelten Schutz hinaus verbessert, ist unklar.

Die immunologische Antwort auf Lebendimpfstoffe kann dadurch eingeschränkt sein, dass bereits im Immunglobulin-Präparat vorhandene Antikörper die attenuierten Impfviren neutralisieren.

Eine Lebendimpfung gegen Gelbfieber kann sinnvoll sein, ist aber selbst bei Vorliegen einer klaren Indikation eine Einzelfallentscheidung in Abhängigkeit vom Ausmaß der Beeinträchtigung der Immunfunktion.

Da auch eine Impfstoff-induzierte $\mathrm{T}$ Zell-Antwort zum Impfschutz beitragen könnte, empfiehlt die STIKO bei Vorliegen einer T-/B-Zell-Restfunktion zusätzlich zur Immunglobulingabe eine jährliche Impfung gegen Influenza sowie eine Grundimmunisierung bzw. ggf. Auffrischimpfung gegen Hepatitis B [8]. Bei vorhandener Indikation ist eine aktive Immunisierung mit dem FSME-Totimpfstoff sinnvoll [9].

Da die in Europa hergestellten Immunglobulinpräparate ausreichende protektive Titer gegen Diphtherie, Tetanus, Pneumokokken, Meningokokken und Haemophilus influenzae Serotyp b vermitteln, sind unter dauerhafter Immunglobulin-Ersatztherapie die Impfungen gegen diese Erkrankungen nicht indiziert [4].

\subsection{Impfungen bei PID-Patienten vor Stammzelltransplantation}

Bei Patienten mit Immundefekten, bei denen aufgrund der spezifischen Diagnose und/oder des klinischen Verlaufs eine Stammzelltransplantation innerhalb der kommenden 3 Monate geplant ist, werden weder Impfungen mit Lebend- noch mit Totimpfstoffen empfohlen. Gründe sind eine mögliche prolongierte Persistenz von attenuierten Impfviren, der zu kurze Zeitraum zum Aufbau einer vollständigen Immunität (deren zelluläre Basis durch die Konditionierung vor der Stammzelltransplantation ohnehin zerstört würde) und die Vermeidung einer Immunstimulation unmittelbar vor Transplantation. Weitere Anwendungshinweise zum Impfen nach autologer oder allogener Stammzelltransplantation werden im Schwerpunktpapier 3 „Impfen bei hämatologischen und onkologischen Grundkrankheiten, solider Organtransplantation, Stammzelltransplantation und Asplenie" gegeben (noch nicht veröffentlicht).

\section{Spezifische Hinweise zum Impfen bei angeborenen Immundefekten}

\subsection{Kombinierte Immundefekte}

Schwere kombinierte Immundefekte („severe combined immunodeficiency“, SCID) sind charakterisiert durch eine ausgeprägte Störung der T-Zell-Immunität, immer kombiniert mit einem humoralen Immundefekt. Andere, weniger schwerwiegende Störungen der T-ZellImmunität mit einem variablen humoralen Immundefekt und meist späterer Manifestation werden als kombinierte Immundefekte („combined immunodeficiency“, CID) zusammengefasst. Bei diesen Erkrankungen besteht ein hohes Risiko für ein weites Spektrum an bakteriellen, viralen, fungalen und parasitären Infektionen [10].

Bei SCID-Erkrankung sind Impfungen aufgrund der schweren Störung der spezifischen Immunität ohne Aussicht auf Erfolg und daher grundsätzlich nicht indiziert. Bei bestimmten, milden CID-Erkrankungen können Totimpfstoffe sinnvoll sein und nach Einzelfallabwägung auch Lebendimpfstoffe verabreicht werden. Zahlreiche Fallbeschreibungen belegen allerdings die Entwicklung z.T. lebensbedrohlicher Komplikationen nach Verabreichung attenuierter Lebendimpfstoffe [3], so dass die Empfehlung einer Lebendimpfung bei CID-Patienten sorgfältig durch entsprechend spezialisierte Ärzte/innen geprüft werden muss.

\subsection{Kombinierte Immundefekte mit syndromalen Erscheinungen}

Bei den heterogenen syndromalen Immundefekten führen die verantwortlichen Gene auch außerhalb des Immunsystems $\mathrm{zu}$ pathologischen Phänotypen, so dass der Immundefekt nur einen Teil der komplexen Erkrankung darstellt. Viele syndromale Immundefekte sind kombinierte Immundefekte (z.B. Wiskott-Aldrich-Syndrom). Hier gelten die Empfehlungen wie unter Abschn. 3.1.

Patienten mit DiGeorge-Syndrom (DGS) haben eine sehr variable Störung der Thymusentwicklung. Nur etwa $5 \%$ zeigen als Neugeborene eine Lymphopenie mit $<1500 \mathrm{~T}-$ Zellen/ $\mu$, noch seltener ist bei diesen Patienten ein klinisch relevanter kombinierter Immundefekt bis hin zum SCID ( $<1 \%)$. Da beim DGS die sich entwickelnden T-Zellen in der Regel eine normale Funktion zeigen, kann die Zahl zirkulierender T-Zellen als Orientierung für eine Impfempfehlung verwendet werden. Dies gilt hingegen nicht für viele andere kombinierte Immundefekte, bei denen neben numerischen auch funktionelle Defizite vorliegen können.

Bei allen Patienten mit DGS sollte unmittelbar bei Diagnosestellung eine Lymphozytentypisierung mit Quantifizierung naiver (CD45RA+) CD4+ T-Zellen erfolgen, um die seltenen schweren Formen ( $<500$ T-Zellen pro $\mu \mathrm{l} ;<20 \%$ naive CD4+ T-Zellen im ersten Lebensjahr) früh zu erfassen. Totimpfstoffe können unabhängig von den Ergebnissen der Lymphozytentypisierung nach den Empfehlungen der STIKO verabreicht werden. Zum Ende des ersten Lebensjahres sollte die Immunantwort auf die Tetanusimpfung bestimmt werden. Bei fehlender pathologischer Infektionsanfälligkeit ${ }^{1}$ können nach Einzelfallabwägung Lebendimpfstoffe auch DGS-Patienten verabreicht werden, die auf Tetanusimpfstoffe Antikörper bilden, > 500 Gesamt-T-Zellen/ $\mu$ l und > 200 CD4+ T-Zellen/ $\mu$ l haben sowie eine normale T-Zell-Proliferation nach Stimulation mit dem Mitogen Phytohämagglutinin (PHA) zeigen [5]. Für diese Patienten lie-

\footnotetext{
1 Leitlinie „Diagnostik von primären Immundefekten" http://www.awmf.org/leitlinien/detail/ II/027-050.html
} 
gen ausreichend Daten zur Verträglichkeit und Serokonversion vor $[11,12]$.

Patienten mit autosomal-dominantem Hyper-IgE-Syndrom haben eine gestörte B-Zell-Differenzierung und fehlende Th17-Zellen. Charakteristische Infektionen sind Staphylokokkenabszesse, bronchopulmonale Infektionen, Candidiasis und pulmonale Aspergillose. Meist ist die Fähigkeit zur Bildung spezifischer Antikörper zumindest zum Teil vorhanden. Die Patienten können daher entsprechend den STIKO-Empfehlungen (einschließlich der Gabe von Lebendimpfstoffen) geimpft werden. Ebenso wird die jährliche Influenza-Impfung empfohlen [5, 13].

\subsection{Erkrankungen mit überwiegendem Antikörpermangel}

Bei der Agammaglobulinämie fehlen in der Regel die B-Zellen und in der Folge die Antikörper. Bakterielle Infektionen, in erster Linie durch bekapselte Erreger im Atemwegstrakt, treten nach den ersten Lebensmonaten auf, wenn der Schutz durch mütterliche Leihantikörper abnimmt. Patienten mit Agammaglobulinämie unter Immunglobulinsubstitution erhalten in der Regel weder Lebend- noch Totimpfstoffe, da teilweise ein passiver Impfschutz besteht bzw. die Impfviren der Lebendimpfstoffe durch die in den Immunglobulin-Präparaten enthaltenen Antikörper neutralisiert werden.

Da eine T-Zell-vermittelte Protektion nach Influenza-Impfung möglich ist, wird die jährliche Influenza-Impfung empfohlen. Aus gleichem Grund sollte auch die Hepatitis B-Impfung durchgeführt werden, d.h. eine anstehende Grundimmunisierung bzw. eine erforderliche Auffrischimpfung erfolgen.

Das variable Immundefektsyndrom („common variable immunodeficiency“, CVID) ist eine heterogene Gruppe von Erkrankungen, welche durch eine Hypogammaglobulinämie verbunden mit einer gestörten Antikörperantwort charakterisiert sind. Leichte Störungen der T-ZellImmunität können auftreten; wenn diese ausgeprägter sind, muss der Patient als CID-Patient klassifiziert werden.

Bei Patienten mit CVID- und nachgewiesener Produktion spezifischer Antikörper können Totimpfstoffe verabreicht werden. Insbesondere konnte bei einigen CVID Patienten auch unter Substitutionstherapie eine Antwort gegen verschiedene Impfstoffe einschließlich Influenza nachgewiesen werden [7]. In Verbindung mit einer möglichen T-Zell-Antwort rechtfertigt dies die Empfehlung zu einer jährlichen Influenza-Impfung sowie zu einer Hepatitis B-Impfung (Grundimmunisierung bzw. Auffrischimpfung; s.o.) auch unter Immunglobulinsubstitution [13, 14].

Als leichtere Formen des Antikörpermangels können IgA-Defizienz, der Immunglobulinsubklassen-Mangel oder der selektive Mangel Polysaccharid-spezifischer Antikörper zusammengefasst werden. Patienten mit diesen leichteren Formen sollten alle Standardimpfungen entsprechend den STIKO-Empfehlungen mit Tot- und Lebendimpfstoffen erhalten $[5,8]$. Wenn noch keine Immunglobulin-Ersatztherapie begonnen wurde, sind zusätzlich Impfungen gegen Meningokokken der Serogruppen ACWY (quadrivalenter Konjugatimpfstoff) und B (Proteinimpfstoff) sowie gegen Pneumokokken empfohlen, wobei hier die sequentielle Impfung mit dem 13-valenten Konjugatimpfstoff (PCV13) gefolgt vom 23-valenten Polysaccharidimpfstoff (PPSV23) nach 6-12 Monaten (ab dem Alter von 2 Jahren) indiziert ist [8].

\subsection{Erkrankungen aufgrund einer gestörten Immunregulation}

In dieser Kategorie immunologischer Störungen werden sehr heterogene Krankheiten zusammengefasst. Hierzu gehören Immundefekte, bei denen Immunkontrollmechanismen gestört sind, ohne dass damit eine wesentlich erhöhte Infektionsanfälligkeit verbunden ist (z.B. Autoimmun-Lymphoproliferatives Syndrom [ALPS]). Bei der ALPS-Erkrankung werden alle Impfungen nach dem STIKO-Impfkalender uneingeschränkt empfohlen. Bei ALPS-Patienten unter immunsuppressiver Therapie gelten die Anwendungshinweise im Schwerpunktpapier 4: „Impfen bei Autoimmunerkrankungen und unter immunmodulatorischer Therapie“.

Darüber hinaus fallen unter diese Kategorie Grundkrankheiten, die neben der
Präsentation von Autoimmunerscheinungen auch mit einer Infektionsanfälligkeit einhergehen (z. B. CD25 Defekt, CTLA-4 Defekt, aktivierende Mutationen des „signal transducer and activator of transcription [STAT]3“-Moleküls, Adenosine Desaminase [ADA]2 Defekt). Die Impfempfehlungen für diese Grundkrankheiten sind wie bei kombinierten Immundefekten (s. Abschn. 3.1), d.h. Totimpfstoffe und in seltenen Einzelfällen auch Lebendimpfstoffe können hier sinnvoll sein.

Ebenfalls in diese Kategorie gehören Krankheiten, bei denen eine Immunstimulation zu schweren, manchmal lebensbedrohlichen Entzündungsschüben führen kann (z. B. familiäre hämophagozytierende Lymphohistiozytose [FHL], Chediak-Higashi-Syndrom (CHS), Griscelli Syndrom Typ 2, X-chromosomal vererbte lymphoproliferative Erkrankungen $[X L P]$, Immunodysregulation-Polyendokrinopathie-Enteropathie-X-Chromosom gekoppeltes Syndrom [IPEX], Interleukin [IL]-10-Rezeptor Defekt). Darüber hinaus wurden beim CHS und beim Typ 3 der FHL nach Impfung z. T. schwer verlaufende Hautgranulome durch Röteln-Impfvirus beobachtet. Bei diesen Immunfunktionsstörungen ist eine hämatopoetische Stammzelltransplantation indiziert und jede vorangehende Lebendimpfung kontraindiziert. Totimpfstoffe sollten spätestens 3 Monate vor Transplantation appliziert werden.

\subsection{Defekte der Zahl oder Funktion von Phagozyten}

Die chronische Neutropenie ist durch eine anhaltende Neutrophilenzahl unter 1500/ $\mu \mathrm{l}$ definiert. Patienten mit kongenitaler Neutropenie haben ein hohes Risiko, an bakteriellen Infektionen - vor allem der Haut und des Atemwegstraktes - zu erkranken. Die septische Granulomatose („chronic granulomatous disease“, CGD) resultiert aus Gendefekten der verschiedenen Untereinheiten der NADPH-abhängigen Phagozytenoxidase (Phox oder NOX2), wodurch u.a. die mikrobiziden Mechanismen von phagozytierenden Zellen (z.B. Granulozyten, Makrophagen, dendritische Zellen) massiv beeinträchtigt werden. Rezidivierende bakterielle Infektionen (u. a. Abszesse der Haut) sind 
die häufigsten Infektionen, ein Drittel der Patienten leidet auch an Pilzinfektionen. Patienten mit kongenitaler Neutropenie oder CGD sollten alle Standardimpfungen nach dem Impfkalender der STIKO erhalten [8]. Da eine spezielle Anfälligkeit gegen Staphylokokken besteht und eine Influenzainfektion schwere Staphylokokkeninfektionen begünstigen kann [15], ist eine jährliche Influenza-Impfung indiziert.

\subsection{Defekte der \\ Pathogenerkennung, der \\ Zytokinproduktion oder der \\ Zytokinsignaltransduktion}

Diese heterogene Gruppe von Immundefekten führt oft zu einer Infektionsanfälligkeit gegenüber bestimmten Erregergruppen.

Defekte der IL-12/Interferon [IFN]- $\gamma$ Achse, entweder bedingt durch Defekte der Zytokinproduktion oder der fehlenden/gestörten Expression des entsprechenden Rezeptors, lösen eine erhöhte Anfälligkeit gegenüber intrazellulären $\mathrm{Pa}$ thogenen (z. B. Mykobakterien, Salmonellen) und Viren aus. Bei diesen Patienten sind alle Lebendimpfstoffe im Gegensatz $\mathrm{zu}$ Totimpfstoffen streng kontraindiziert [16].

Defekte des Typ I Interferonsystems führen ebenfalls besonders zur Anfälligkeit gegenüber Viren. Sämtliche Lebendimpfungen sind kontraindiziert. Schwere klinische Folgen einer Impfung gegen Masern-Mumps-Röteln (MMR) wurden z. B. bei Patienten mit STAT2 Defizienz dokumentiert [17].

Weiterhin sollten Lebendimpfungen nicht bei Patienten mit aktivierenden STAT1 Mutationen durchgeführt werden; für diese Patienten sind ebenfalls schwere Impfmasern beschrieben [18].

Defekte der Pathogen-Erkennungsrezeptoren (z.B. Defekte in der Signalübertragung der Toll-like Rezeptor-Familie wie IRAK-4 oder MyD88 Defekt) bedingen eine besondere Anfälligkeit gegenüber invasiven bakteriellen Infektionen, insbesondere Pneumokokken und Staphylokokken $[8,19]$. Bei diesen Defekten sind vor allem zeitgerechte, sequentielle Pneumokokkenimpfungen essentiell [8], auch wenn die Impfung bei diesen Patienten keinen vollständigen Schutz gegen invasive Pneumokokkenerkrankungen (IPD) aufbauen kann [20]. Aufgrund des erhöhten IPD-Risikos nach Influenzainfektion [21] wird außerdem eine jährliche Influenza-Impfung empfohlen. Des Weiteren sollten diese Patienten die Meningokokken-Impfungen MenACWY sowie MenB erhalten. Eine MenACWY-Auffrischimpfung nach 5 Jahren sollte erwogen werden $[5,22]$.

\subsection{Autoinflammatorische Erkrankungen}

Autoinflammatorische Erkrankungen (z. B. Familiäres Mittelmeerfieber und verwandte Erkrankungen) werden u. a. durch Defekte im Bereich des Inflammasoms ausgelöst und gehen mit einer überschießenden Produktion von proinflammatorischen Zytokinen (z.B. Interleukin-1) einher. Die gestörte Entzündungsregulation bei autoinflammatorischen Erkrankungen führt zu spontanen Fieberepisoden und Entzündungserscheinungen in verschiedenen Organen. Erkrankungsschübe können durch Immunstimulation hervorgerufen bzw. verstärkt werden. Hierzu gehören auch Impfungen mit Totund Lebendimpfstoffen. In Abwägung von Risiko und Nutzen sind Impfungen aber außerhalb von akuten Erkrankungsschüben möglich. Zur Planung der Impfungen ist jedoch die Kontaktaufnahme zu einem im Bereich der autoinflammatorischen Erkrankungen spezialisierten Zentrum empfohlen. Für Patienten unter immunsuppressiver Therapie gelten die im Schwerpunktpapier 4 „Impfen bei Autoimmunerkrankungen und unter immunmodulatorischer Therapie“ diskutierten Hinweise (Publikation in Vorbereitung).

\subsection{Komplementdefekte}

Defekte der frühen Komponenten der Komplementkaskade (z.B. C3) prädisponieren aufgrund der beeinträchtigten Opsonisierungsleistung zu invasiven Infektionen mit bekapselten Bakterien, insbesondere Streptococcus pneumoniae und Haemophilus influenzae Typ b. Patienten mit Defekten der terminalen Komponenten der Komplementkaskade (C5-9-Kom- plex) haben ein sehr stark erhöhtes Risiko für invasive Infektionen mit Meningokokken. C3- und C5-defiziente Patienten weisen darüber hinaus auch eine beeinträchtigte Typ 1 T-Helferzell-Antwort auf [23, 24].

Patienten mit angeborenen Komplementdefekten sollten alle von der STIKO empfohlenen Impfungen uneingeschränkt erhalten. Falls die Grundimmunisierung gegen Pneumokokken im Kindesalter nicht mit dem 13-valenten Pneumokokken-Konjugatimpfstoff (PCV13) erfolgte, sollten diese Patienten in jedem Fall mit PCV13 geimpft werden (je nach Alter mit einer oder zwei Impfstoffdosen, siehe Fachinformationen des Herstellers). Nach 6-12 Monaten ist zusätzlich die sequentielle Impfung mit dem 23-valenten Polysaccharidimpfstoff (PPSV23) entsprechend den STIKO-Empfehlungen indiziert. Eine Auffrischimpfung mit PPSV23 alle 6 Jahre ist empfohlen.

Ebenso sollten Patienten mit angeborenen Komplementdefekten bereits im Säuglingsalter mit einem tetravalenten Meningokokken-Konjugatimpfstoff (ACWY) geimpft werden. Für die Grundimmunisierung mit Nimenrix ${ }^{\circledast}$ sind bis zu einem Alter von 12 Monaten 3 Impfstoffdosen notwendig. Ab einem Alter von 12 Monaten bzw. 2 Jahren (Nimenrix ${ }^{\circledast}$ bzw. Menveo $^{\circledast}$ ) sollte eine zweimalige Impfung im Abstand von 8 Wochen erfolgen. Eine Auffrischimpfung gegen Meningokokken ACWY sollte alle 5 Jahre erfolgen [5].

Zusätzlich sollte eine Impfung gegen Meningokokken des Serotyps B entsprechend den STIKO-Empfehlungen und unter Berücksichtigung der Fachinformation (Zulassung von Bexero ${ }^{\circledR}$ ab 2 Monaten, von Trumenba ${ }^{\oplus}$ ab 10 Jahre) verabreicht werden [8].

Eine Übersicht finden Sie in $\bullet$ Tab. 1.

\section{Impfung von Kontaktpersonen und Postexpositionsprophylaxe}

Die Impfung enger Kontaktpersonen ist eine wichtige Maßnahme zum Schutz von Patienten mit PID. Gesunde immunkompetente Individuen, die mit einem PID-Patienten im gemeinsamen Haushalt leben, sollten entsprechend den Empfehlungen der STIKO geimpft sein, ein- 
schließlich der jährlichen Impfung mit einem inaktivierten Influenza-Impfstoff (Kokon-Strategie) [8]. Falls mit einem nasalen Influenza-Lebendimpfstoff geimpft wurde, sollte der Kontakt zu immunsupprimierten Patienten für 7 Tage vermieden werden [25].

Personen, welche Kontakt zu Patienten mit einer PID-bedingten Kontraindikation für Varizellenimpfung haben, sollten selbst gegen Varizellen geschützt sein. Ist aufgrund einer negativen Impfanamnese bzw. nicht durchgemachten Erkrankung eine Varizellenimpfung notwendig, sollte anschließend für 14 Tage der Kontakt zu PID-Patienten konsequent vermieden werden, da in seltenen Fällen Impfvarizellen auch bei Immunkompetenten auftreten und übertragen werden können [26].

Nach Varizellen-Exposition von nicht immunen Kontaktpersonen sollten diese eine postexpositionelle Varizellen-Impfung erhalten. Bestand der Kontakt bereits 2 Tage vor Auftreten eines Exanthems beim Indexfall, ist die postexpositionelle Impfung innerhalb von 5 Tagen nach Exposition zu verabreichen. Bei Kontakt zu einem Indexfall mit bereits bestehendem Exanthem sollte die Impfung innerhalb von 3 bis max. 5 Tagen nach Exposition erfolgen und der Kontakt zu PID-Patienten für ca. 3-4 Wochen vermieden werden.

Nach direktem Kontakt eines nicht immunen PID-Patienten zu einer an Varizellen erkrankten Person ist die postexpositionelle Gabe eines Varicella-ZosterImmunglobulins indiziert. Die Gabe sollte möglichst innerhalb der ersten 3 Tage bis max. 10 Tage nach Exposition erfolgen.

Bei erwachsenen Personen mit positiver Varizellen-Anamnese und Kontakt zu ungeschützten PID-Patienten kann eine Impfung gegen Herpes zoster mit dem adjuvantierten rekombinanten SubunitTotimpfstoff (Shingrix ${ }^{\circledR}$ ) erwogen werden. Der Impfstoff ist ab dem Alter von 50 Jahren zugelassen.

Weitere Lebendimpfungen (Mumps, Masern, Röteln, Gelbfieber) können gesunden Kontaktpersonen ohne Gefahr für den PID-Patienten verabreicht werden. Stillende Mütter dürfen nicht gegen Gelbfieber geimpft werden.

\section{Hinweise zu Reiseimpfungen}

Reiseimpfungen mit Totimpfstoffen können problemlos appliziert werden. Abhängig von der Funktionsstörung des Immunsystems muss aber damit gerechnet werden, dass keine protektive Immunantwort aufgebaut wird.

\subsection{Gelbfieber}

Die Gelbfieberimpfung ist eine Lebendimpfung und sollte bei Vorliegen eines primären Immundefektes nur in Einzelfällen und nach gründlicher Nutzen-Risiko-Abwägung erfolgen.

Nach den internationalen Gesundheitsbestimmungen (International Health Regulations) ist zur Einreise in bestimmte Länder eine Gelbfieber-Impfung vorgesehen. Bei medizinischer Kontraindikation besteht die Möglichkeit einer Impfbefreiung. Das „exemption certificate“ ist in englischer oder französischer Sprache im internationalen Impfpass einzutragen. Die Länder, für die Impfpflicht besteht, sind zur Anerkennung dieses Zeugnisses nicht verpflichtet.

\subsection{Tollwut (Rabies)}

Eine Impfung gegen Tollwut wird bei Reisen in Endemiegebiete empfohlen.
Die präexpositionelle Impfung (mit HDCoder PCEC-Impfstoff) erfolgt nach dem in der Fachinformation genannten Impfschema (3 Impfstoffdosen, Tag 0, 7, 28). Ein Schnell-Impfschema (off-label) wird nicht empfohlen.

Bei immundefizienten Personen sollte eine Antikörperbestimmung 2-4 Wochen nach der vollständigen Grundimmunisierung erfolgen. Bei einem Antikörperspiegel von $<0,5 \mathrm{IE} / \mathrm{ml}$ ist eine erneute Impfung indiziert. Bei Indikation eines länger benötigten Impfschutzes werden Auffrischimpfungen 1 Jahr nach der ersten Impfung und dann jeweils im Abstand von 5 Jahren mit je einer Impfstoffdosis empfohlen. Alternativ kann auch die Notwendigkeit der Auffrischimpfung durch Bestimmung der Antikörper im Serum festgelegt werden.

Im Rahmen einer Postexpositionsprophylaxe sollen immundefizienten Personen 5 Impfstoffdosen verabreicht werden (Essen-Schema: Tag 0, 3, 7, 14, 28). Eine simultane Gabe von Immunglobulinen ist bereits ab Expositionsgrad II indiziert. Hierbei sollte entsprechend den genauen Empfehlungen der Fachinformationen gehandelt werden. Zwei Wochen nach der letzten Impfung ist eine Kontrolle der Impfantwort empfohlen, da Fälle von Nichtansprechen beobachtet wurden.

\subsection{Typhus, Cholera}

Die oralen Lebendimpfstoffe gegen Typhus (Typhoral ${ }^{\circledR}$ ) und Cholera (Vaxcho$\mathrm{ra}^{\circledR}$; in Dtl. bisher nicht zugelassen) sind bei Vorliegen eines primären Immundefektes grundsätzlich kontraindiziert. Gegen Typhus steht ein inaktivierter parenteraler Impfstoff, gegen Cholera ein inaktivierter oraler Impfstoff (Dukoral ${ }^{\oplus}$ ) zur Verfügung. 
Tab. 1 Impfindikationen und Anwendungshinweise bei verschiedenen Primären Immundefekten. Anmerkung: Bei den Totimpfstoffen werden hier nur die Indikationsimpfungen, nicht aber die Standardimpfungen der STIKO wie z. B. Impfungen gegen Tetanus, Diphtherie und Pertussis aufgeführt. Diese können bei PID-Patienten ohne Risiko eingesetzt werden, sind allerdings bei schweren kombinierten Immundefekten ohne schützende Wirkung. Die Angaben zu den Lebendimpfungen beziehen sich auf Standardimpfungen der STIKO (Impfungen gegen Rotavirus, MMR und Varizellen) sowie auf Indikationsimpfungen wie z. B. die Gelbfieberimpfung

\begin{tabular}{|c|c|c|c|c|}
\hline Erkrankungen & $\begin{array}{l}\text { Totimpfstoffe (Indikations- } \\
\text { impfungen) }\end{array}$ & $\begin{array}{l}\text { Lebendimpfstof- } \\
\text { fe (einschließlich } \\
\text { Influenza) }\end{array}$ & Auffrischimpfung & $\begin{array}{l}\text { Referenzen, Experten- } \\
\text { konsens (EK) }\end{array}$ \\
\hline $\begin{array}{l}\text { Schwere Kombinierte Im- } \\
\text { mundefekte }\end{array}$ & Nicht sinnvoll & K & - & EK \\
\hline Kombinierte Immundefekte & Influenza; Herpes zoster & $\mathrm{E}^{\mathrm{a}}$ & Influenza: jährlich & EK \\
\hline DiGeorge-Syndrom & $\begin{array}{l}\text { Influenza; Pneumokokken }{ }^{\text {b; }} \\
\text { Meningokokken ACWY und B; } \\
\text { Herpes zoster }\end{array}$ & $\mathrm{E}^{\mathrm{a}}$ & $\begin{array}{l}\text { Influenza: jährlich } \\
\text { Pneumokokken: alle } 6 \text { Jahre PPSV23 }\end{array}$ & EK, $[27,28]$ \\
\hline Hyper-IgE-Syndrom & $\begin{array}{l}\text { Influenza; Pneumokokken }{ }^{\text {b; }} \\
\text { Herpes zoster }\end{array}$ & I & $\begin{array}{l}\text { Influenza: jährlich } \\
\text { Pneumokokken: alle } 6 \text { Jahre PPSV23 }\end{array}$ & [5] \\
\hline Agammaglobulinämie & Influenza, Hepatitis B & Nicht sinnvoll & Influenza: jährlich & EK \\
\hline $\begin{array}{l}\text { Common variable immuno- } \\
\text { deficiency (CVID) }\end{array}$ & $\begin{array}{l}\text { Influenza; Pneumokokken }{ }^{\text {b; }} \\
\text { Meningokokken ACWY und B; } \\
\text { Hepatitis B }\end{array}$ & $\begin{array}{l}\text { Nach sicherer } \\
\text { Abgrenzung zu ei- } \\
\text { nem kombinierten } \\
\text { Immundefekt }^{\mathrm{a}}\end{array}$ & $\begin{array}{l}\text { Influenza: jährlich } \\
\text { Hepatitis B: Auffrischimpfung } \\
\text { Pneumokokken: alle } 6 \text { Jahre PPSV23 }\end{array}$ & {$[5,8,28]$} \\
\hline $\begin{array}{l}\text { Familiäre Hämophagozytose- } \\
\text { Syndrome (FHL) IPEX }\end{array}$ & $I^{d}$ & K & & EK \\
\hline $\begin{array}{l}\text { Autoimmun-lymphoprolife- } \\
\text { ratives Syndrom (ALPS) }\end{array}$ & $I^{d}$ & $I^{d}$ & & EK \\
\hline Neutropenie & $\begin{array}{l}\text { Influenza; Pneumokokken }{ }^{\text {b; }} \\
\text { Herpes zostere }\end{array}$ & 1 & $\begin{array}{l}\text { Influenza: jährlich } \\
\text { Pneumokokken: alle } 6 \text { Jahre PPSV23 }\end{array}$ & {$[27]$} \\
\hline Septische Granulomatose & $\begin{array}{l}\text { Influenza; Pneumokokken }{ }^{\text {b; }} \\
\text { Herpes zoster }\end{array}$ & I & $\begin{array}{l}\text { Influenza: jährlich } \\
\text { Pneumokokken: alle } 6 \text { Jahre PPSV23 }\end{array}$ & {$[5,27,28]$} \\
\hline $\begin{array}{l}\text { Defekte des Toll-like Rezep- } \\
\text { tor Signalwegs }\end{array}$ & $\begin{array}{l}\text { Meningokokken ACWY und } \\
\text { B; Pneumokokken }{ }^{\text {b }} \text { Herpes } \\
\text { zoster }^{\mathrm{e}}\end{array}$ & 1 & $\begin{array}{l}\text { Meningokokken ACWY: alle } 5 \text { Jahre } \\
\text { Pneumokokken: alle } 6 \text { Jahre PPSV23 }\end{array}$ & {$[5,10,27]$} \\
\hline $\begin{array}{l}\text { Defekte des Interferon- } \\
\text { Signalwegs }\end{array}$ & 1 & $\mathrm{~K}$ & & EK, [17] \\
\hline $\begin{array}{l}\text { Autoinflammatorische } \\
\text { Erkrankungen }\end{array}$ & $I^{d}$ & $I^{d}$ & & EK \\
\hline Komplement-Defekte & $\begin{array}{l}\text { zweimalige Impfung gegen } \\
\text { Meningokokken ACWY im } \\
\text { Abstand von } 8 \text { Wochen, Imp- } \\
\text { fung gegen Meningokokken B; } \\
\text { Pneumokokken }{ }^{b}\end{array}$ & 1 & $\begin{array}{l}\text { Meningokokken ACWY: alle } 5 \text { Jahre } \\
\text { Pneumokokken: alle } 6 \text { Jahre PPSV3 }\end{array}$ & {$[5,8,28]$} \\
\hline \multicolumn{5}{|c|}{$\begin{array}{l}\text { I indiziert, } K \text { kontraindiziert, } E \text { Einzelfallentscheidung, d. h. Risiko-Nutzen-Abwägung durch einen in der Behandlung von Immundefekten erfah } \\
\text { EK Expertenkonsens } \\
\text { a Bei Nachweis einer normalen Impfantwort auf Totimpfstoffe (Tetanus) und }>C D 3+T \text {-Zellen/ } \mu l,>200 \text { CD4+ T-Zellen/ } \mu \text { l und normaler T-Zell-P } \\
\text { Grenzwerte für Lymphozyten beziehen sich auf Kinder im Alter von 1-6 Jahren) } \\
\text { b Die STIKO empfiehlt für Patienten mit Immundefizienz die sequentielle Impfung mit PCV13 (Pneumokokken-Konjugatimpfstoff) und nach 6- } \\
\text { (Pneumokokken-Polysaccharidimpfstoff, ab } 2 \text { Jahren) } \\
\text { c Diese Diagnose kann erst ab dem 4. Lebensjahr gestellt werden und erfordert die Abgrenzung von einem kombinierten Immundefekt (CID) } \\
\text { d Jede Impfung, aber nach Abwägung der möglichen Auslösung eines Entzündungsschubs der Grundkrankheit } \\
\text { e Eine Anwendung des Herpes zoster-Totimpfstoffs im Alter unter } 50 \text { Jahren stellt einen off-label-use dar. }\end{array}$} \\
\hline
\end{tabular}




\section{Impfen bei HIV-Infektion}

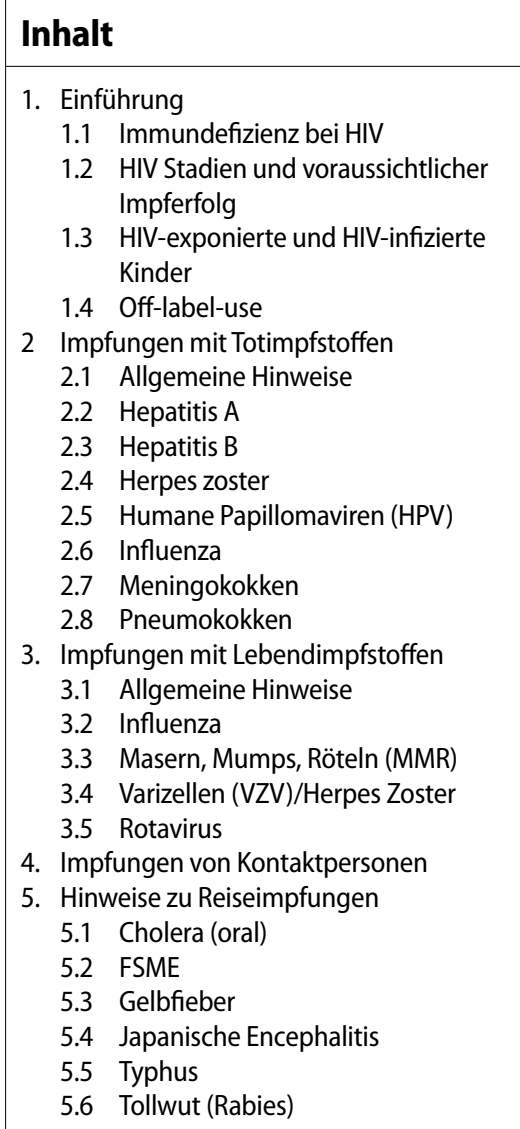

\section{Einführung}

\subsection{Immundefizienz bei HIV- Infektion}

Eine nicht therapierte, mehrjährige, chronisch persistierende Virämie löst im Verlauf der HIV-Infektion eine schwere Immundefizienz und in der Folge das erworbene Immundefektsyndrom (acquired immunodeficiency syndrome, AIDS) aus. Eine antiretrovirale Therapie (ART) führt zu einer signifikanten Reduktion der HIVirusreplikation und damit zu einem Anstieg der CD4+ T-Lymphozyten, verbunden mit einer Stabilisierung der Immunsystems.

Bei unbehandelter HIV-Infektion kommt es im Zuge der HI-Virusvermehrung zu einer kontinuierlich fortschreitenden Depletion und Dysfunktion infizierter CD4+ T-Lymphozyten [29] sowie zu einer zunehmenden Beeinträchtigung des zellulären und humoralen Immunsystems [30, 31]. Selbst bei erfolgter Grundimmunisierung werden die erregerspezifische Immunität sowie die generelle Infektionsabwehr mit fortschreitender Immundefizienz abnehmen $[30,32]$.

\subsection{HIV Stadien und voraussichtlicher Impferfolg}

Die HIV-bedingte Immundefizienz und die zu erwartenden Impferfolge werden bei Erwachsenen in Abhängigkeit von der Anzahl an CD4+ T-Lymphozyten im Blut in verschiedene Stadien unterteilt (s. - Tab. 2)

Bei HIV-positiven Personen sind die Impfantworten oft schwächer, fallen niedriger aus und halten weniger lange an als bei nicht mit HIV infizierten Personen. Daher ist es sinnvoll, eine Impfung baldmöglichst nach einer durch ART erreichten Immunrekonstitution vorzunehmen, um eine optimale Immunantwort zu erzielen [34]. Bei einigen Impfungen (z. B. Influenza) wurde postvakzinal eine transiente Erhöhung der HI-Viruslast ohne Krankheitsprogression beobachtet [35, 36]. Daher ist die transiente Erhöhung der HI-Viruslast nach Impfung nicht als Argument gegen eine Impfung zu werten.

Mittels quantitativer Antikörperbestimmungen, wie z.B. nach einer Hepatitis B- oder Hepatitis A-Impfung, kann die
Qualität der Impfantwort eingeschätzt werden.

\subsection{HIV-exponierte und HIV- infizierte Kinder}

HIV-exponierte Kinder sind Kinder HIVpositiver Mütter. Exponierte Kinder, deren HIV-Infektionsstatus noch nicht abschließend geklärt ist, sollen in den ersten 10 Lebensmonaten alle Standardimpfungen einschließlich der Rotavirusimpfung ohne Verzögerung erhalten [37, 38]. Spätestens im Alter von 11 Monaten ist der Infektionsstatus i.d. R. geklärt (meistens bereits nach 4 Monaten), so dass zu diesem Zeitpunkt über die weiteren anstehenden Lebendimpfungen entschieden werden kann. Die Zulässigkeit der MMRV-Lebendimpfungen bei HIV-positiven Kindern oder Kindern mit unklarem HIV-Infektionsstatus wird unter Abschn. 3.1 diskutiert.

Um bei HIV-infizierten Kindern die Bedeutung der CD4+ T-Lymphozytenzahl richtig einschätzen zu können, ist eine altersgruppenabhängige Interpretation der CD4+ T-Lymphozytenzahl notwendig. Diese Werte variieren zwischen den Altersgruppen $<1$ Jahr, 1 bis $<6$ Jahren und $\geq 6$ Jahre (s. - Tab. 3). Dabei ist zu beachten, dass bei Kindern ab 6 Jahren die absoluten Zellzahlen und die prozentualen Anteile an CD4+ T-Zellen den Wer-
Tab. 2 Zu erwartender Impferfolg in Abhängigkeit der CD4+T-Lymphozytenzahl bei Erwachsenen (CDC-Klassifikation [33])

\begin{tabular}{llll}
$\begin{array}{l}\text { CD4+ T-Lymphozyten- } \\
\text { zahl } / \mu \mathrm{l}\end{array}$ & $\begin{array}{l}\text { Zu erwartende } \\
\text { Impfantwort }\end{array}$ & $\begin{array}{l}\text { Kategorie (CDC- } \\
\text { Klassifikation) }\end{array}$ & $\begin{array}{l}\text { Kontraindikation für } \\
\text { Impfstoffe }\end{array}$ \\
\hline$>500$ & normal & A1, B1 & nein \\
$200-499$ & gut & A2, B2, C2 & nein \\
$<200$ & geringer & A3, B3, C3 & Lebendimpfstoffe
\end{tabular}

Tab. 3 HIV-Stadien-Einteilung nach altersabhängiger CD4+ T-Lymphozytenzahl bei Kindern (Quelle: CDC [39])

\begin{tabular}{|c|c|c|c|c|c|c|}
\hline \multirow[t]{3}{*}{ Stadium } & \multicolumn{6}{|c|}{ Alter zum Zeitpunkt der Kontrolle der CD4+ T-Zellzahl } \\
\hline & \multicolumn{2}{|l|}{$<1 \mathrm{Jahr}$} & \multicolumn{2}{|c|}{1 bis $<6$ Jahre } & \multicolumn{2}{|l|}{$\geq 6$ Jahre } \\
\hline & $\mathrm{CD} 4+/ \mu \mathrm{l}$ & $\%^{a}$ & $\mathrm{CD} 4+/ \mu \mathrm{l}$ & $\%^{\mathrm{a}}$ & $\mathrm{CD} 4+/ \mu \mathrm{l}$ & $\%^{\mathrm{a}}$ \\
\hline 1 & $\geq 1500$ & $\geq 34$ & $\geq 1000$ & $\geq 30$ & $\geq 500$ & $\geq 26$ \\
\hline 2 & 750-1499 & $26-33$ & $500-999$ & $22-29$ & $200-499$ & $14-25$ \\
\hline 3 & $<750$ & $<26$ & $<500$ & $<22$ & $<200$ & $<14$ \\
\hline
\end{tabular}


ten von Erwachsenen entsprechen. Nach der aktualisierten CDC-Klassifikation von 2014 soll zur Abschätzung der Schwere der Immunsuppression vor allem die absolute CD4+ T-Zellzahl herangezogen werden [39].

Der prozentuale Anteil der CD4+ TZellen spielt in der aktualisierten CDC Klassifikation eine untergeordnete Rolle und sollte nur berücksichtigt werden, wenn die korrespondierenden absoluten CD4+ T-Zellzahlen fehlen. Da in der Vergangenheit eine schwere Immunsuppression u.a. als eine CD4+ T-Zellzahl $<15 \%$ in allen Altersgruppen im Kindesalter definiert wurde (CDC Klassifikation 1994) und dies auch in vielen Studien zur Effektivität und Sicherheit von Impfstoffen berücksichtigt wurde, wird diese Grenze von $<15 \%$ bei Impfempfehlungen als Definition für eine schwere Immunsuppression im Kindesalter weiterhin oft verwen$\operatorname{det}[37,38]$.

Generell sollten die Impfungen bei HIV-infizierten Kindern nach den Empfehlungen der STIKO erfolgen und Verzögerungen im Impfschema möglichst vermieden werden. Dies schließt die Rotavirusimpfung von Säuglingen ein [40, 41].

Vor Gabe von Lebendimpfungen muss jedoch der Grad der Immunsuppression berücksichtigt werden. Eine schwere Immunsuppression unter Berücksichtigung der absoluten CD4+ T-Zahl (• Tab. 3) läge somit bei einer absoluten CD4+ TZellzahl von $\leq 750 / \mu \mathrm{l}$ im Alter $<12$ Monate, $\leq 500 / \mu \mathrm{l}$ im Alter von 1 bis $<6$ Jahre und $<200 / \mu \mathrm{l}$ im Alter $\geq 6$ Jahren vor. Unter diesen Bedingungen sind Lebendimpfstoffe bei HIV-infizierten Kindern aufgrund des potentiellen Risikos von Impfstoff-assoziierten Erkrankungen kontraindiziert.

Bei HIV-infizierten Kindern ist grundsätzlich bei allen Impfungen mit verminderten und kürzer anhaltenden Impfantworten zu rechnen $[42,43]$, so dass der Impferfolg alle 1-2 Jahre kontrolliert werden und ggf. Boosterimpfungen durchgeführt werden sollten.

Wenn die HIV-Diagnose bei älteren Kindern gestellt wird, sollten die Antikörperkonzentrationen von impfpräventablen Erkrankungen, gegen die die Kinder nach den STIKO-Empfehlungen geimpft sein sollten, bestimmt werden. Bei Fehlen von Impfantigen-spezifischen Antikör- pern sollen die Impfungen entsprechend den Empfehlungen für das jeweilige Alter nachgeholt werden. Um die Effektivität der Impfungen zu steigern, sollten diese Impfungen möglichst erst nach Einleitung der ART, erfolgreicher Viruslastsuppression und einem Anstieg der CD4+ Zellzahl auf $>15 \%$ der Gesamtlymphozytenzahl erfolgen.

\subsection{Off-label-use}

Wenn zur Umsetzung der STIKO-Empfehlungen bzw. dieser Anwendungshinweise die Verabreichung von Impfstoffen außerhalb des von den nationalen oder europäischen Zulassungsbehörden genehmigten Gebrauchs (Off-label-use) notwendig ist, ist die vorherige umfassende ärztliche Aufklärung und Beratung des Patienten bzw. seiner Sorgeberechtigten über Nutzen und Risiken der Impfung und des geplanten Off-label-Gebrauchs unabdingbar und müssen in der Patientenakte umfassend dokumentiert werden. Weiterhin sollte die Einwilligung idealerweise durch die Unterschrift des Patienten bzw. seines Sorgeberechtigten bestätigt werden.

Im nachfolgenden Text sowie in der Tabelle ist ein etwaiger Off-label-Gebrauch entsprechend gekennzeichnet.

\section{Impfungen mit Totimpfstoffen}

\subsection{Allgemeine Hinweise}

Totimpfstoffe können bei HIV-infizierten Personen generell in allen Stadien der HIV-Infektion sicher eingesetzt werden, auch bei einer schweren Immundefizienz [44]. Der Impfstatus sollte daher entsprechend den Empfehlungen der STIKO vervollständigt werden.

Da mit einer eingeschränkten Immunantwort zu rechnen ist, sollte eine Kontrolle der Immunantwort und ggf. eine Wiederholung der Impfung (z. B. Hepatitis B-Impfung) nach einer durch ART erreichten Stabilisierung des Immunsystems durchgeführt werden. Es konnte gezeigt werden, dass Boosterimpfungen sehr gut vertragen werden und effektiv sind [45].

Totimpfstoffe können auch HIV-positiven Schwangeren verabreicht werden, wobei spezielle Indikationen, z. B. für die
Influenzaimpfung, nach den Empfehlungen der STIKO berücksichtigt werden sollten $[44,46]$.

\subsection{Hepatitis A}

Die Hepatitis A-Impfung wird HIV-Patienten bei Vorliegen weiterer Risikofaktoren (z. B. Männer, die Sex mit Männern haben [MSM], Reisen in Endemiegebiete oder chronische Lebererkrankungen) empfohlen. Diese Gruppen haben ein erhöhtes Risiko für eine Hepatitis A-Infektion bzw. -Erkrankung. Eine HIV-Infektion führt nicht per se zu schwereren Krankheitsverläufen einer Hepatitis A, aber zu einer verlängerten Virämie [47].

Die Serokonversionsraten nach Impfung bei HIV-Patienten sind geringer als bei Nicht-HIV-Infizierten und abhängig von der CD4+ T-Zellzahl bei Impfung [48, 49].

Für die Hepatitis A-Impfung kann ein monovalenter Hepatitis A-Impfstoff bzw. ein Hepatitis A+B-Kombinationsimpfstoff verwendet werden. Die Immunantwort gegenüber Hepatitis A ist bei Verwendung des monovalenten Hepatitis A-Impfstoffs erfolgversprechender als bei Verwendung des Kombinationsimpfstoffs, insbesondere bei Patienten mit niedrigen CD4+ T-Zellzahlen und einer nachweisbaren Viruslast $[50,51]$. Der monovalente Hepatitis A-Impfstoff wird bei Immungesunden in einem 2-Dosen-Schema (0, 6-12 Monate) verabreicht, während bei HIV-Infizierten das empfohlene Impfschema vom Immunstatus des Infizierten abhängt. Unterschieden werden zwei Impfschemata für Patienten mit einer CD4+ T-Zellzahl $>350$ Zellen/ $\mu$ l bzw. $<350$ Zellen/ $\mu \mathrm{l}$.

HIV-Infizierte mit einer CD4+ TZellzahl > 350 Zellen/ $\mu$ l:

Hier wird eine zweimalige Impfung mit einem monovalenten Hepatitis AImpfstoff im Abstand von 6-12 Monaten empfohlen [44, 52].

HIV-Infizierte mit einer CD4+ TZellzahl <350 Zellen/ $\mu$ l:

Bei diesen Personen sollte eine 3-malige Impfung mit dem monovalenten $\mathrm{He}$ patitis A-Impfstoff nach dem Schema 0, 1, 6 Monate erwogen werden. Studien ergaben, dass sich die bei Immunsuppression eingeschränkte Serokonversionsrate sowie die erzielten Antikörperkonzentrationen bei Personen mit niedrigen 
CD4+ T-Zellzahlen durch Anwendung eines 3-Dosen-Impfschemas verbessern $[51,53]$. Bei einem fortlaufend bestehenden Risiko sollte in Abhängigkeit vom Immunstatus nach 5-jährigem Intervall eine Antikörperbestimmung und ggf. eine Booster-Impfung erfolgen [54, 55].

Zur Impfung gegen Hepatitis A kann auch ein Hepatitis $\mathrm{A}+\mathrm{B}-$ Kombinationsimpfstoff verwendet werden, wenn der $\mathrm{Pa}$ tient noch keinen Hepatitis B-Impfschutz hat. Dabei sollte jedoch berücksichtigt werden, dass der Impfschutz gegen Hepatitis A nicht so schnell aufgebaut wird wie bei Verwendung eines monovalenten Impfstoffes und dass insbesondere bei Immunsupprimierten der Impferfolg unsicher ist. Die Kombinationsimpfung sollte daher nur bei Patienten mit CD4+ T-Zellzahlen $>500$ Zellen/ $\mu$ l verwendet werden. Für die Kombinationsimpfung ist ein 3-DosenSchema (0, 1, 6 Monate) empfohlen. Zur Überprüfung des Impferfolgs sollte nach Abschluss der Impfserie eine Hepatitis A-Antikörper-Kontrolle erfolgen. Ist die Antikörperkonzentration noch nicht zufriedenstellend $(<20 \mathrm{mIU} / \mathrm{ml})$, sollte eine weitere Impfung mit einem monovalentem Hepatitis A-Impfstoff erfolgen.

Untersuchungen mit HIV-infizierten MSM ergaben, dass trotz einer verspäteten Immunantwort auf die Hepatitis A-Impfung das Risiko einer Hepatitis A-Infektion während eines akuten Infektionsausbruches signifikant reduziert werden konnte [54].

Als Postexpositionsprophylaxe (PEP) nach einem Risikokontakt wird eine Hepatitis A-Impfung empfohlen (so schnell wie möglich, bis 14 Tage nach Exposition) [56]. Bei HIV-Patienten mit einer CD4+ T-Zellzahl <200 Zellen/ $\mu$ l wird eine zusätzliche Gabe von humanem Immunglobulin (HNIG) empfohlen [44, 56].

\subsection{Hepatitis B}

Die STIKO empfiehlt die Hepatitis B-Impfung auch für HIV-positive Personen, da Hepatitis B-Koinfektionen aufgrund der gleichartigen Transmissionsroute von HIV und Hepatitis B häufig auftreten (bei $5-10 \%$ in den USA, $20-30 \%$ in Asien) und eine chronische Hepatitis B-Infektion die Leber-assoziierte Mortalität bei HIVinfizierten Personen erhöht [57].
Die Impfung gegen Hepatitis B ruft bei ca. $30 \%$ der HIV-infizierten Personen mit einer CD4+ T-Zellzahl $<500$ Zellen/ $\mu \mathrm{l}$ eine nur ungenügende Immunantwort hervor [58]. Daher sollte 4 bis 8 Wochen nach durchgeführter Grundimmunisierung mit einem altersentsprechenden Impfstoff eine Antikörperbestimmung vorgenommen werden [59]. Bei einem Anti-HBs-Wert $<100$ IE/l nach Grundimmunisierung wird eine 4. Impfstoffdosis empfohlen. Bei fehlendem Antikörperanstieg nach 4-8 Wochen können folgende Impfoptionen erwogen werden: (a) 5. Gabe eines Hepatitis B-Impfstoffs, der eine höhere Antigenmenge $(40 \mu \mathrm{g})$ enthält (HBVaxPro 40,) mit erneuter Antikörperkontrolle nach 4-8 Wochen; (b) Wechsel zu einem stärker adjuvantierten Impfstoff (z. B. Fendrix [Off Label-use, da nur für Dialyse-Patienten zugelassen]); (c) Impfung mit der trivalenten Hepatitis BVakzine Sci-B-Vac ${ }^{\mathrm{TM}}$, die in Deutschland nicht zugelassen ist $[44,60-63]^{1}$.

Studiendaten deuten darauf hin, dass bei HIV-infizierten Kindern und Jugendlichen, die keine ausreichende Immunantwort nach Hepatitis B-Impfung entsprechend den STIKO-Empfehlungen (Impfung 0, 1, 6-12 Monate) bilden, die Serokonversionsrate bei einem erneuten Boostern mit der Entwicklung von zytotoxischen T-Gedächtniszellen korreliert $[60,64]$.

Zum Schutz vor Hepatitis B können sowohl monovalente und bei Patienten mit einer CD4+ T-Zellzahl >500 Zellen/ $\mu \mathrm{l}$ auch $\mathrm{A}+\mathrm{B}-$ Kombinationsimpfstoffe verwendet werden. Kombinationsimpfstoffe werden gut vertragen und können bei Einhaltung und Vollständigkeit des Standardimpfschemas (Impfung 0, 1, 6 Monate) ebenfalls zu einer ausreichenden Immunantwort führen $[65,66]$.

\subsection{Herpes zoster}

Im Frühjahr 2018 wurde ein adjuvantierter rekombinanter Totimpfstoff (Shingrix ${ }^{\circledast}$ ) zum Schutz vor Herpes zoster und postherpetischer Neuralgie für Personen

\footnotetext{
1 enthält alle drei Epitope des Hepatitis B-Oberflächen-Antigens [prä-S1, prä-S2 und S]; Vertrieb durch Sci-Vac Ltd., Import über internationale Apotheken
}

ab 50 Jahren in der EU zugelassen. Die Ergebnisse der Zulassungsstudien belegen die hohe Effektivität des Impfstoffs bei immunkompetenten Erwachsenen ( $>50$ Jahre) und Senioren (>70 Jahre) $[67,68]$.

Im Rahmen einer Phase I/II Studie unter HIV-infizierten Patienten im Alter $\geq 18$ Jahren wurde dieser als immunogen und sicher bewertet [69]. Da es sich um einen Totimpfstoff handelt, ist eine Impfung von HIV-Patienten nicht kontraindiziert und ist nach Meinung der an diesen Anwendungshinweisen beteiligten Experten sinnvoll. Eine Anwendung bei Patienten im Alter von unter 50 Jahren stellt jedoch einen Off-Label-Gebrauch dar.

Die STIKO führt aktuell eine erneute Risiko-Nutzen-Bewertung der Impfung gegen Herpes zoster unter Berücksichtigung der Daten zum neuen Totimpfstoff durch, nachdem sich die Kommission 2017 gegen die Verwendung des Herpes Zoster Lebendimpfstoffs als Standardimpfung ausgesprochen hatte [70].

\subsection{Humane Papillomviren (HPV)}

Bei HIV-infizierten Personen ist eine deutlich höhere Prävalenz von anogenitalen HPV Infektionen dokumentiert als bei HIV-negativen Personen [71, 72]. Insbesondere bei MSM liegt das Infektionsrisiko für HPV signifikant höher als in der übrigen Bevölkerung [73]. Auch Folgeerkrankungen einer persistierenden HPV-Infektion treten bei HIV-infizierten MSM häufiger auf als bei HIV-negativen Personen: 35-52 \% der HIV-positiven MSM haben höhergradige anale Dysplasien (AIN 2/3), und die Analkarzinom-Inzidenz liegt bei diesen Personen bei über 100 Neuerkrankungen pro 100.000 pro Jahr [74].

Von der STIKO wird die HPV-Impfung für alle Mädchen und Jungen im Alter von 9-14 Jahren empfohlen. Nachholimpfungen sollten bis zum Alter von 17 Jahren erfolgen.

Die STIKO hat bislang noch keine systematische Evidenz-Aufarbeitung für Personengruppen ab dem Alter von 18 Jahren durchgeführt, die möglicherweise von einer HPV-Indikationsimpfung profitieren könnten. Bei HIV-positiven Personen erscheint eine HPV-Impfung sinnvoll, da ein deutlich erhöhtes Analkarzinom-Ri- 
siko, insbesondere bei MSM, beschrieben ist [75].

Es gibt zahlreiche Daten zur HPVImpfung von HIV-Infizierten. In Studien konnte die Immunogenität und Verträglichkeit der HPV-Impfung bei HIV-positiven Personen belegt werden [76-79]. In einer Studie unter HIV-positiven Männern (unter ART CD4+-T-Zellzahl $\geq 200 /$ $\mu \mathrm{l}$, ohne ART $>350 / \mu \mathrm{l})$, die eine negative HPV-PCR und -Serologie hatten, zeigten sich Serokonversionsraten, die vergleichbar mit denen von HIV-negativen Personen waren [79]. Nach Meinung der an diesen Anwendungshinweisen beteiligten Experten sollten daher HIV-Patienten gegen HPV-geimpft werden. Es muss jedoch bedacht werden, dass der Impfstoff nicht gegen im Impfstoff enthaltene HPV-Typen schützt, wenn bereits vor Impfung eine HPV-Infektion mit diesen Typen stattgefunden hat. Des Weiteren kann die protektive Wirkung der Impfung möglicherweise in Abhängigkeit vom Immunstatus eingeschränkt sein. So zeigte eine Studie an HIV-positiven Frauen, dass die Serokonversionsrate bei Frauen mit einer CD4+-T-Zellzahl $\leq 200 /$ $\mu$ geringer war als bei Frauen mit einer CD4+-T-Zellzahl >200/ $\mu \mathrm{l}$ [77].

Alle zugelassenen HPV-Impfstoffe können bei HIV-Infizierten eingesetzt werden [80, 81]. Der Patient/die Patientin bzw. Arzt/Ärztin sollte vor Beginn der Impfserie bei HIV-Patienten ab 18 Jahre die Übernahme der Kosten mit der jeweiligen Krankenkasse klären.

Sowohl der bivalente (Cervarix ${ }^{\circ}$ ) als auch der nonavalente (Gardasil9 $9^{\circ}$ HPVImpfstoff sehen für die Grundimmunisierung von Personen ab 15 Jahren 3 Impfstoffdosen vor, je nach Impfstoff mit dem Impfschema 0-1-6 bzw. 0-2-6 Monate. Mädchen und Jungen, die bei der ersten HPV-Impfung 14 Jahre oder jünger sind, benötigen nur 2 Impfstoffdosen im Abstand von mindestens 5 Monaten. Bisher wird davon ausgegangen, dass keine weiteren (Booster-) Impfungen notwendig sind.

\subsection{Influenza}

Für Menschen mit einer HIV-Infektion sowie für ihre Kontaktpersonen wird von der STIKO eine jährliche Influenzaimpfung mit einem quadrivalenten Influen-
za-Impfstoff empfohlen [46, 82]. Influenza-Totimpfstoffe sind sicher und gut verträglich, die Antikörpertiter können bei HIV-positiven Personen jedoch niedriger ausfallen als bei HIV-negativen. Diese korrelieren mit der CD4+ T-Zellzahl und der HI-Viruslast [83, 84].

HIV-infizierte Kinder sollen ab dem Alter von 6 Monaten jährlich gegen Influenza geimpft werden. Entsprechend der Fachinformation des jeweils verwendeten Impfstoffs sollen Kinder, die noch nie gegen Grippe geimpft wurden, nach einem Zeitraum von mindestens 4 Wochen eine zweite Dosis bekommen. Dies gilt auch für HIV-negative Kinder. Zur Anwendung des nasalen Lebendimpfstoffs siehe unten (Kap. 3, Impfungen mit Lebendimpfstoffen).

\subsection{Meningokokken}

HIV-infizierte Personen haben ein erhöhtes Risiko für invasive Meningokokken-Erkrankungen, das mit abnehmender CD4+ T-Zellzahl zunimmt [85]. Das Risiko war bei einer Studie in den USA bei HIV-Infizierten etwa zehnmal so hoch wie in der Allgemeinbevölkerung [86]. Darüber hinaus sind schwere Verläufe häufiger und die Letalität höher [87].

Insbesondere ist bei HIV-infizierten MSM das Risiko für invasive Meningokokken-Erkrankungen erhöht, was in Rahmen von Ausbrüchen beobachtet wurde [88-90]. Es gibt zusätzlich Hinweise, dass Meningokokken sexuell übertragbar sind. So ist das Auftreten solcher Fälle bereits in Frankreich, Spanien und Deutschland beschrieben [89, 91, 92].

Nach den STIKO-Empfehlungen sollte bei HIV-Patienten eine Impfung sowohl gegen Meningokokken der Serogruppen ACWY als auch der Serogruppe B durchgeführt werden $[46,93]$.

Die Immunogenität und die Sicherheit von MenACWY-Impfstoffen konnten in Studien auch bei HIV-Patienten nachgewiesen werden $[93,94]$.

Die im 2. Lebensjahr von der STIKO empfohlene Impfung gegen MenC sollte bei HIV-infizierten Kindern durch die MenACWY ersetzt werden. Kinder, die a priori eine MenC-Impfung erhalten hatten, sollten eine zusätzliche MenACWYImpfung erhalten.
Eine einmalige MenACWY-Impfung wird als ausreichend angesehen, auch wenn Studien bei HIV-Infizierten niedrigere Immunantworten auf MenC- oder MenACWY-Konjugatimpfstoffe als bei Immungesunden zeigten [93, 94]. Im Einzelfall, d. h. bei CD4+ T-Zellzahlen $<200 / \mu l$ bzw. $<15 \%$ bei Kindern, kann daher eine zweimalige Impfung mit 4-valentem Konjugatimpfstoff MenACWY im Abstand von 8 Wochen sowie ein Boosterimpfung nach 5 Jahren erwogen werden [5, 44, 95].

Für die MenB-Impfung liegen derzeit Immunogenitätsdaten nur für Patienten mit Komplementdefekten oder Asplenie, jedoch nicht für Patienten mit einer HIVInfektion vor. Die Impfserie der MenBImpfung besteht je nach Alter der zu impfenden Person aus 2 bis 4 Impfstoffdosen (vgl. Fachinformation zu Bexsero ${ }^{\circ}$ ); bei Verwendung des Impfstoffs Trumenba (zugelassen ab dem Alter von 10 Jahren) ist das 3-Dosen-Schema anzuwenden.

\subsection{Pneumokokken}

HIV-infizierte Erwachsene und Kinder haben verglichen mit der Allgemeinbevölkerung ein erhöhtes Risiko für invasive Pneumokokken-Erkrankungen (IPD), welches auch unter ART besteht [96-99]. Niedrige CD4+ T-Lymphozytenzahl und hohe HIVViruslast sind die Hauptrisikofaktoren für eine IPD bei HIV [100]. Das Risiko wird durch vermeidbare Faktoren, wie z. B. Rauchen oder Alkohol, weiter erhöht [96, 101].

Bei HIV-infizierten Personen wird von der STIKO die sequenzielle Impfung mit dem 13-valenten Pneumokokken-Konjugatimpfstoff (PCV13) gefolgt vom 23-valenten Pneumokokken-Polysaccharidimpfstoff (PPSV23) nach 6-12 Monaten empfohlen. PPSV23 kann bei Kindern erst ab dem Alter von 2 Jahren appliziert werden. Auch bei einer CD4+ T-Zellzahl $<200$ Zellen/ $\mu$ l sollen beide Impfungen durchgeführt werden, da gerade bei niedrigen $\mathrm{CD} 4+\mathrm{T}$-Zellzahlen das Risiko für eine invasive Pneumokokkeninfektion sehr hoch ist [102] und es keine Hinweise für eine Beeinträchtigung der Schutzwirkung beider Impfstoffe bei CD4+T-Lymphopenie gibt [102-106]. Aufgrund der zeitlichen Begrenzung des Impfschutzes ist eine Auffrischimpfung mit PPSV23 alle 6 Jahre empfohlen [8]. 
Eine Übersicht der Anwendungshinweise $\mathrm{zu}$ Impfungen mit Totimpfstoffen bei HIV-Infizierten finden Sie in • Tab. 4.

\section{Impfungen mit Lebendimpfstoffen}

\subsection{Allgemeine Hinweise}

Lebendimpfstoffe sind bei HIV-infizierten Personen mit einer schweren Immunsuppression (s. Tab. 2 und 3 HIV-Stadium 3) bzw. bei Vorliegen einer AIDS-definierenden Erkrankung aufgrund des Risikos von Impfstoff-assoziierten Erkrankungen kontraindiziert (Komplikationen siehe „Impfen bei Immundefizienz (I) Grundlagenpapier, - Tab. 1; [3]). Die Impfung mit einem Lebendimpfstoff sollte verschoben werden, bis sich die CD4+ T-Lymphozyten-Zellzahl durch eine ART verbessert hat und eine kontrollierte Viruslast bis $<200 \mathrm{Kopien} / \mathrm{ml}$ erreicht worden ist.

\subsection{Influenza}

Für das Kindesalter steht auch ein nasal $\mathrm{zu}$ applizierender lebendattenuierter Influenzaimpfstoff (LAIV) zu Verfügung und kann auf der Basis der aktuellen STIKO-Empfehlungen eingesetzt werden. Laut Fachinformation sollte der Impfstoff nicht bei symptomatischer HIV-Infektion verabreicht werden. Bei Personen mit asymptomatischer HIV-Infektion besteht hingegen keine Kontraindikation. Im Rahmen einer Studie unter HIV-positiven Kindern im Alter von $>5$ bis $<18$ Jahre mit einer CD4+-T-Zellzahl $>200 / \mu \mathrm{l}$ bzw. $>15 \%$ wurde der Impfstoff als sicher und ausreichend immunogen bewertet [107]. Entsprechend der Fachinformation sollen Kinder, die zuvor noch nicht gegen saisonale Influenza geimpft wurden, frühestens nach 4 Wochen eine zweite Dosis verabreicht bekommen.

\subsection{Masern, Mumps, Röteln (MMR)}

Der attenuierte MMR-Lebendimpfstoff sollte HIV-exponierten Kindern entsprechend den Empfehlungen der STIKO verabreicht werden. Auch HIV-infizierte Kinder können gegen MMR geimpft werden, sofern sie zum Zeitpunkt der Impfung keine schwere Immunsuppression aufweisen (s. - Tab. 2). Bei HIV-infizierten Kindern ist mit verminderten und kürzer anhaltenden Impfantworten zu rechnen [42, 43], so dass der Impferfolg alle 1-2 Jahre kontrolliert werden und ggf. Boosterimpfungen durchgeführt werden sollten.

Bei HIV-infizierten Erwachsenen sollte beim ärztlichen Erstkontakt anhand der Anamnese bzw. des Impfpasses der Masern-Mumps-Röteln-Status überprüft werden. Falls in der Kindheit nur eine MMR-Impfung verabreicht wurde, ist eine einmalige MMR-Nachholimpfung indiziert, wobei die CD4+ T-Zellzahl $>200 / \mu l$ betragen sollte. Eventuell kann auch eine serologische Testung sinnvoll sein, wobei zu beachten ist, dass bei nicht ausreichenden Antikörperspiegeln ein monovalenter Impfstoff gegen nur einen der Erreger nicht zur Verfügung steht. Bei seronegativen Erwachsenen mit einer CD4+ T-Zellzahl >200 Zellen/ $\mu$ l sollten 2 MMR-Impfungen durchgeführt werden $[5,28,44,108]$.

Nichtimmunen Kinder und Erwachsenen, welche unmittelbar nach einer Masernexposition nicht aktiv geimpft werden können, wird eine postexpositionelle passive Immunisierung mit Standardimmunglobulinen $(1 \times 400 \mathrm{mg} / \mathrm{kg} \mathrm{KG}$ intravenös) empfohlen. Diese sollte so schnell wie möglich (möglichst innerhalb von 6 Tagen nach Exposition) erfolgen [109].

\subsection{Varizellen (VZV)/Herpes zoster}

Basierend auf den Impfempfehlungen Großbritanniens und der USA ist die Impfung gegen Varizellen mit einem monovalenten Lebendimpfstoff bei asymptomatischen HIV-infizierten Erwachsenen mit einer CD4+ T-Zellzahl $>200 / \mu$ und Kindern möglich, sofern sich diese nicht im Stadium 3 ( $\bullet$ Tab. 2 und 3 ) befinden $[44,108,110]$. Der Impferfolg sollte serologisch kontrolliert werden.

Bei erwachsenen HIV-Patienten mit negativer Varizellen-Anamnese oder Seronegativität kann unter wirksamer ART eine zweimalige VZV-Impfung im Abstand von mindestens 1 Monat (6-8 Wochen) erwogen werden. Erwachsene $\mathrm{Pa}$ tienten mit einer CD4+ T-Zellzahl $<200$ Zellen/ $\mu \mathrm{l}$ bzw. Kinder mit einer schweren Immunsuppression (s. oben) oder symptomatische HIV-positive Patienten (Pa- tienten im CDC-Stadium B oder C) dürfen nicht gegen Varizellen geimpft werden.

Es gibt bislang nur wenige Daten zur Sicherheit und Effektivität der Varizellenimpfung bei HIV-infizierten Erwachsenen. Die verfügbaren Studien zeigen aber, dass die Impfung bei >200-400 CD4+ TZellen/ $\mu$ bei Patienten unter einer wirksamen ART sicher und effektiv ist [111]. Bei schwangeren Frauen ist die VZV-Impfung generell kontraindiziert.

Bei Varizellen-Exposition von VZVseronegativen HIV-Infizierten empfiehlt es sich, möglichst früh (innerhalb von 3 Tagen bis maximal 10 Tage nach Exposition) eine PEP durch passive Immunisierung mit Varicella-Zoster-Virus Immunglobulin durchzuführen [8].

Zur Prävention des Herpes zoster bei Personen mit HIV sollte der Lebendimpfstoff nicht mehr verwendet werden. Mit der Zulassung des inaktivierten rekombinanten VZV-Impfstoffes (Shingrix ${ }^{\circledR}$ ) in Europa ist auch eine Impfung gegen Herpes zoster von HIV-positiven Patienten im CDC-Stadium 3 der Immunsuppression möglich (s. Abschn. 2.4).

\subsection{Rotavirus}

Die Impfung gegen Rotavirus kann bei HIV-infizierten Säuglingen durchgeführt werden [37] mit Ausnahme schwer immunsupprimierter Säuglinge (siehe Abschn. 1.3).

Eine Übersicht der Anwendungshinweise $\mathrm{zu}$ Impfungen mit Lebendimpfstoffen bei HIV-Infizierten finden Sie in - Tab. 5.

\section{Impfungen von Kontaktpersonen}

Eine umfassende und vollständige Impfprophylaxe von Kontaktpersonen in der Umgebung von HIV-infizierten Menschen ist eine wichtige Schutzmaßnahme gegenüber HIV- und AIDS-Patienten, insbesondere gegenüber Patienten, die nicht geimpft werden können. Der Impfstatus sollte entsprechend den STI$\mathrm{KO}$-Empfehlungen vervollständigt (insbesondere der Masern-Impfschutz) und jährlich aktualisiert (z. B. Influenzaimpfung) werden. 
HIV-positive Personen im Stadium 3 sollten den Kontakt mit dem Stuhl von Kindern nach Rotavirus-Impfung in den ersten 14 Tagen nach der 1 . Impfung vermeiden [112].

\section{Hinweise zu Reiseimpfungen}

\subsection{Cholera (oral)}

Die Impfung sollte entsprechend der gültigen STIKO-Empfehlung allen Personen im Rahmen der reisemedizinischen Beratung angeboten werden, die ein er- höhtes Risiko für eine Cholera-Infektion besitzen (z. B. Einsätze als Katastrophenhelfer in Cholera-Endemie-Gebieten, Arbeit in Flüchtlingslagern), unabhängig von der vorliegenden CD4+ T-Zellzahl, durchgeführter ART oder der Höhe der HI-Viruslast. Es gibt nur wenige Daten zur Immunogenität und Sicherheit des in Deutschland zugelassenen inaktivierten $\mathrm{WC} / \mathrm{rBS}$ Impfstoffs (Dukoral ${ }^{\circledR}$ ) bei HIV-Infizierten. Studiendaten belegen, dass bei HIV-Infizierten mit einer CD4+ T-Zellzahl >100 Zellen/ $\mu$ und dem regulären Zwei-Dosis-Impfschema eine Anti- körperantwort gegen das Choleratoxin erreicht werden kann $[113,114]$.

\subsection{FSME}

Lebt ein Patient in einem FSME-RisikoGebiet [115] oder ist ein dortiger Aufenthalt geplant, wird die Impfung gegen FSME mit einem der beiden verfügbaren Totimpfstoffe (FSME-IMMUN ${ }^{\circledR}$, ENCE$\mathrm{PUR}^{\circledR}$ ) empfohlen. Die Grundimmunisierung sollte dabei mit 3 Impfstoffdosen $(0$, 1-3 und 5-12 bzw. 9-12 Monate je nach Impfstoff) durchgeführt werden. Bei HIV-

Tab.4 Impfindikationen und Anwendungshinweise für Personen mit HIV

\begin{tabular}{|c|c|c|c|c|}
\hline $\begin{array}{l}\text { Totimpfstoffe (Indi- } \\
\text { kationsimpfungen) }\end{array}$ & Anwendungshinweise & $\begin{array}{l}\text { Von den STIKO-Empfehlun- } \\
\text { gen abweichend bzw. abwei- } \\
\text { chende Impfschemata }\end{array}$ & Serologische Kontrolle sinnvoll ja/nein/wann & Literatur \\
\hline Hepatitis A & $\begin{array}{l}\text { Impfung entsprechend } \\
\text { STIKO }\end{array}$ & 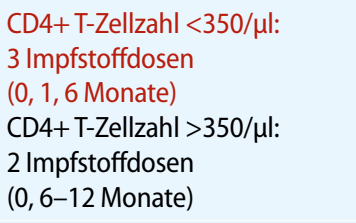 & $\begin{array}{l}\text { Serologische Kontrolle nach } 5 \text { Jahren, ggfs. } \\
\text { Booster-Impfung }\end{array}$ & {$[46,48,51]$} \\
\hline Hepatitis B & $\begin{array}{l}\text { Impfung entsprechend } \\
\text { STIKO sofern Standard- } \\
\text { impfung (im Säuglings- } \\
\text { alter) nicht durchgeführt } \\
\text { wurde }\end{array}$ & & $\begin{array}{l}\text { Antikörperkontrolle vor und 4-8 Wochen nach } \\
\text { durchgeführter Grundimmunisierung: Anti-HBs } \\
<100 \text { IE/l: } 4 \text {. Impfstoffdosis; Kontrolle nach 4-8 } \\
\text { Wo; erneut fehlender Antikörperanstieg: } 5 \text {. Gabe } \\
\text { mit } 40 \mu \text { g Antigen enthaltendem Impfstoff oder } \\
\text { Wechsel zu stärker adjuvantiertem Impfstoff } \\
\text { (Fendrix, Off-label-use) oder Wechsel zu Sci-B-Vac } \\
\text { (HepB prä-S1-prä-S2-S-Vakzine) }{ }^{a}\end{array}$ & $\begin{array}{l}{[44,46,49,} \\
108,126]\end{array}$ \\
\hline Herpes zoster & $\begin{array}{l}\text { Kann in Erwägung } \\
\text { gezogen werden. Im Alter } \\
\text { unter } 50 \text { Jahren Off-Label } \\
\text { Gebrauch }\end{array}$ & & & \\
\hline HPV & $\begin{array}{l}\text { Entsprechend STIKO für } \\
\text { alle Kinder im Alter 9-14 } \\
\text { (bis 17) Jahre. Darüber } \\
\text { hinaus kann die Impfung } \\
\text { für HIV-positive Frauen } \\
\text { und Männer ab } 18 \text { Jahre } \\
\text { erwogen werden (Einzel- } \\
\text { fallentscheidung) }\end{array}$ & $\begin{array}{l}\text { ab } 18 \text { Jahre Einzelfallentschei- } \\
\text { dung }\end{array}$ & & {$[44,46,80]$} \\
\hline Influenza & $\begin{array}{l}\text { Jährliche Impfung ent- } \\
\text { sprechend STIKO }\end{array}$ & & & $\begin{array}{l}{[44,46,83,} \\
94]\end{array}$ \\
\hline $\begin{array}{l}\text { Meningokokken } \\
\text { ACWY-Konjugatimpf- } \\
\text { stoff, MenB-Impfstoff } \\
\text { (individuelle Risikoab- } \\
\text { schätzung) }\end{array}$ & $\begin{array}{l}\text { Impfung entsprechend } \\
\text { STIKO }\end{array}$ & $\begin{array}{l}\text { CD4+ T-Zellzahl <200/ } \mu \text { l: zwei- } \\
\text { malige Impfung im Abstand } \\
\text { von } 8 \text { Wochen sowie Booster } \\
\text { nach } 5 \text { Jahren } \\
\text { anstelle der MenC-Impfung im } \\
\text { 2. Lj. Impfung mit MenACWY }\end{array}$ & & $\begin{array}{l}{[5,46,93} \\
95,127]\end{array}$ \\
\hline Pneumokokken & $\begin{array}{l}\text { Entsprechend STIKO: } \\
\text { Sequentielle Impfung mit } \\
\text { PCV13 und PPSV23 nach } \\
\text { 6-12 Monaten. PPSV23 ab } \\
\text { dem Alter von } 2 \text { Jahren }\end{array}$ & & & $\begin{array}{l}{[36,46,} \\
128,129]\end{array}$ \\
\hline
\end{tabular}


Tab.5 Impfindikationen und Anwendungshinweise für Personen mit HIV

\begin{tabular}{|c|c|c|c|c|}
\hline Lebendimpfstoffe & Anwendungshinweise & $\begin{array}{l}\text { Von den STIKO-Empfehlun- } \\
\text { gen abweichend bzw. abwei- } \\
\text { chende Impfschemata }\end{array}$ & Serologische Kontrolle sinnvoll ja/nein/wann & Literatur \\
\hline Influenza (LAIV) & $\begin{array}{l}\text { kontraindiziert bei symp- } \\
\text { tomatischer HIV-Infektion }\end{array}$ & & & $\begin{array}{l}\text { Fachinfor- } \\
\text { mation }\end{array}$ \\
\hline $\begin{array}{l}\text { Masern, Mumps, } \\
\text { Röteln (Kinder) }\end{array}$ & $\begin{array}{l}\text { entsprechend STIKO- } \\
\text { Empfehlung, wenn nicht } \\
\text { HIV-Stadium } 3\end{array}$ & & $\begin{array}{l}\text { Antikörperkontrolle nach 1-2 Jahren, ggfs. } \\
\text { Boosterimpfung }\end{array}$ & {$[41,42]$} \\
\hline $\begin{array}{l}\text { Masern, Mumps, Rö- } \\
\text { teln (Indikationsimp- } \\
\text { fung für Erwachsene) }\end{array}$ & 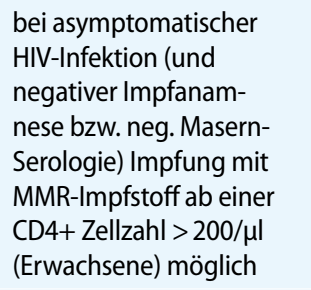 & $\begin{array}{l}\text { zweimalige Impfung im Ab- } \\
\text { stand von mind. } 4 \text { Wochen }\end{array}$ & $\begin{array}{l}\text { serologische Kontrolle bei ärztlichem Erstkontakt } \\
\text { vor eventueller Impfung }\end{array}$ & {$[44,130]$} \\
\hline Herpes zoster & kontraindiziert & $\begin{array}{l}\text { (Herpes zoster-Lebendimp- } \\
\text { fung }\left[\text { Zostavax }^{\circledast}\right] \text { nicht von der } \\
\text { STIKO empfohlen) }\end{array}$ & & {$[65,66]$} \\
\hline $\begin{array}{l}\text { Varizellen (Indika- } \\
\text { tionsimpfung für } \\
\text { Erwachsene) }\end{array}$ & 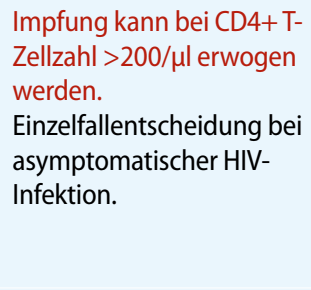 & $\begin{array}{l}\text { zweimalige Impfung im } \\
\text { Abstand von mind. } 1 \text { Monat } \\
\text { (6-8 Wochen) } \\
\text { HIV-Infizierte sind bisher von } \\
\text { der STIKO als Indikationsgrup- } \\
\text { pe bei der Varizellen-Impfung } \\
\text { im Erwachsenenalter nicht } \\
\text { genannt }\end{array}$ & & $\begin{array}{l}{[44,111} \\
131]\end{array}$ \\
\hline Rotavirus & $\begin{array}{l}\text { entsprechend STIKO- } \\
\text { Empfehlungen }\end{array}$ & & & [37] \\
\hline
\end{tabular}

infizierten Patienten mit einer CD4+ TZellzahl <200/ $\mu$ (CDC-Stadium 3) kann (wie auch bei anderen immunsupprimierten Patienten) 30 bis 60 Tage nach der 2. Impfung eine Messung der Antikörperkonzentration in Betracht gezogen werden. Falls eine schützende Antikörperkonzentration nicht erreicht wurde, kann die Verabreichung einer zusätzlichen Impfstoffdosis erwogen werden (siehe entsprechende Fachinformationen der verfügbaren FSME-Impfstoffe) $[44,116,117]$.

\subsection{Gelbfieber}

Asymptomatischen HIV-Patienten mit einer CD4+ T-Zellzahl $>200 / \mu$ l und einer durch eine ART erfolgreich supprimierten HI-Viruslast kann die Gelbfieberimpfung verabreicht werden [118]. Über einen Todesfall nach Gelbfieberimpfung eines HIV-Patienten mit <200 CD4+ T-Zellen/ $\mu \mathrm{l}$ wurde aus Thailand berichtet [119].

Abhängig von der CD4+ T-Zellzahl kann die Immunantwort herabgesetzt sein $[118,120]$. Daher sollte bei HIV-Patienten nicht wie sonst von einem lebenslangen Impfschutz ausgegangen werden, sondern bei weiterhin bestehendem Expositionsrisiko nach 10 Jahren eine Auffrischimpfung erfolgen [44, 121, 122].

Bei Reisen in Endemiegebiete sollte eine strenge Risikoabwägung vorgnommen werden. Nach den internationalen Gesundheitsbestimmungen (International Health Regulations) ist zur Einreise in bestimmte Länder eine Gelbfieber-Impfung vorgesehen. Bei medizinischer Kontraindikation besteht die Möglichkeit einer Impfbefreiung. Das „exemption certificate" ist in englischer oder französischer Sprache im internationalen Impfpass einzutragen. Die Länder, für die Impfpflicht besteht, sind zur Anerkennung dieses Zeugnisses nicht verpflichtet.

\subsection{Japanische Enzephalitis}

Für die Impfung gegen Japanische Enzephalitis liegt derzeit keine Empfehlung der
STIKO vor. Bei längerfristigem Aufenthalt im Endemiegebiet (Süd-, Südost- und Ostasien) oder bei Reisen mit erhöhter Exposition (z.B. Übernachtung in ländlichen Regionen der Endemiegebiete, speziell während der Regenzeit und danach) kann eine Impfung gegen Japanische Enzephalitis in Betracht gezogen werden [123]. Es gibt jedoch keine gesicherten Daten zur Immunogenität und Sicherheit des Totimpfstoffes bei HIV-infizierten Erwachsenen. Daten zu HIV-infizierten Kindern zeigen aber, dass die Impfung in dieser Personengruppe sicher und immunogen ist [124]. Geimpft werden kann nach dem Standardschema, d.h. 2 Impfstoffdosen im Abstand von 28 Tagen sowie eine Auffrischimpfung nach 12-24 Monaten [44]. Das zugelassene Schnellschema mit zwei Impfungen an Tag 0 und 7 sollte nicht angewendet werden, da es hierzu keine Daten bei Personen mit HIV-Infektion gibt. 


\subsection{Typhus}

Bei HIV-Infizierten ist eine reisemedizinische Empfehlung zur parenteralen Typhus-Impfung (Vi-Polysaccharidvakzine) mit dem Totimpfstoff bei Reisen in Entwicklungsländer und bei Reisen in Länder mit deutlich erhöhtem Typhusrisiko großzügiger zu stellen als bei HIV-Nichtinfizierten. Die Impfung wird nach den Vorgaben der Fachinformation ungeachtet der CD4+ T-Zellzahl, der HI-Viruslast und der ART durchgeführt (einmalige Impfung, Zulassung für Kinder ab dem Alter von 2 Jahren, Booster nach 3 Jahren) [44]. Bei einer CD4+ T-Zellzahl $<200 / \mu \mathrm{l}$ soll eine Auffrischimpfung bei Risikopersonen nach 2 Jahren erfolgen [28]. Der orale Typhus-Lebendimpfstoff (Typhoral $\mathrm{L}^{\circledR}$ ) ist kontraindiziert.

\subsection{Tollwut (Rabies)}

Bei Reisen in Risikogebiete wird eine Impfung gegen Rabies/Tollwut von der STIKO empfohlen. Die Impfung (mit HDC oder PCEC Impfstoff) erfolgt nach dem in der Fachinformation genannten Impfschema (3 Impfstoffdosen, Tag 0, 7, 28). Ca. 4-8 Wochen nach der letzten Gabe sollte eine Antikörperbestimmung erfolgen. Bei einem Spiegel $<0,5 \mathrm{IE} / \mathrm{ml}$ wird eine weitere Impfstoffdosis empfohlen.

Im Rahmen einer Postexpositionsprophylaxe sollte Personen mit Immundefizienz bereits ab Expositionsgrad II die Simultanprophylaxe mit 5 Impfstoffdosen (Tag 0, 3, 7, 14, 28) und Immunglobulin (Tag 0 bis spätesten 7) verabreicht werden. Zwei Wochen nach der letzten Impfung ist eine Kontrolle der Impfantwort empfohlen, da Fälle von Impfversagen beschrieben wurden [125].

\section{Korrespondenzadresse}

\section{Dr. Jane Hecht}

Robert Koch-Institut, Berlin, Deutschland HechtJ@rki.de

Interessenkonflikt. Die Autoren geben keine Interessenskonflikte an.

Danksagung. Das Autorenteam bedankt sich herzlich bei allen weiteren mitarbeitenden Experten der STIKO-Arbeitsgemeinschaft Immundefi- zienz für das Einbringen ihrer Expertise und die kontinuierliche, konstruktive Zusammenarbeit. Großer Dank gilt auch allen Mitarbeiterlnnen des Fachgebietes Impfprävention am Robert Koch-Institut für ihre fachliche Unterstützung und kritische Durchsicht des Papiers und Herrn Prof. N. Brockmeyer von der Ruhr-Universität Bochum für seine Beiträge im Kapitel 2 Impfen bei HIVInfektion. Zudem danken wir Frau E. Wetzel und Frau A. Thomas für ihre redaktionelle Durchsicht.

\section{Literatur}

1. Reda SM, Cant AJ (2015) The importance of vaccination and immunoglobulin treatment for patients with primary immunodeficiency diseases (PIDs)-World PI Week April 22-29, 2015. Eur J Immunol 45(5):1285-1286

2. Sarmiento JD, Villada F, Orrego JC, Franco JL, Trujillo-Vargas CM (2016) Adverse events following immunization in patients with primary immunodeficiencies. Vaccine 34(13):1611-1616

3. Niehues T, Bogdan C, Hecht J, Mertens T, Wiese-Posselt M, Zepp F (2017) Impfen bei Immundefizienz: Anwendungshinweise zu den von der Ständigen Impfkommission empfohlenen Impfungen(I) Grundlagenpapier. Bundesgesundheitsblatt Gesundheitsforschung Gesundheitsschutz 60(6):674-684

4. Medical Advisory Committee of the Immune Deficiency F, Shearer WT, Fleisher TA, Buckley RH, Ballas Z, Ballow M et al (2014) Recommendations for live viral and bacterial vaccines in immunodeficient patients and their close contacts. J Allergy Clin Immunol 133(4):961-966

5. Rubin $L G$, Levin MJ, Ljungman P, Davies EG, Avery R, Tomblyn M et al (2014) 2013 IDSA clinical practice guideline for vaccination of the immunocompromised host. Clin Infect Dis 58(3):309-18, e44-100

6. Picard C, Gaspar BH, Al-Herz W, Bousfiha A, Casanova JL, Chatila T et al (2018) International Union of Immunological Societies: 2017 Primary Immunodeficiency Diseases Committee Report on Inborn Errors of Immunity. J Clin Immunol 38(1):96-128

7. Goldacker $S$, Draeger R, Warnatz K, Huzly D, Salzer U, Thiel J et al (2007) Active vaccination in patients with common variable immunodeficiency (CVID). Clin Immunol 124(3):294-303

8. Robert Koch-Institut (2018) Empfehlungen der Ständigen Impfkommission (STIKO) am RKI 2018/2019. Epidemiologisches Bulletin, 34/2018

9. Seidel MG, Grohmann E, Sadeghi K, Pollak A, Heitger A, Forster-Waldl E (2010) Vaccination against tick-borne encephalitis virus tests specific lgG production ability in patients under immunoglobulin substitution therapy. Vaccine 28(40):6621-6626

10. Chinn IK, Shearer WT (2015) Severe combined immunodeficiency disorders. Immunol Allergy Clin North Am 35(4):671-694

11. Al-Sukaiti N, Reid B, Lavi S, Al-Zaharani D, Atkinson A, Roifman CM et al (2010) Safety and efficacy of measles, mumps, and rubella vaccine in patients with DiGeorge syndrome. J Allergy Clin Immunol 126(4):868-869

12. Perez EE, Bokszczanin A, McDonald-McGinn D, Zackai EH, Sullivan KE (2003) Safety of live viral vaccines in patients with chromosome $22 q 11.2$ deletion syndrome (DiGeorge syndrome/velocardiofacial syndrome). Pediatrics 112(4):e325

13. Beck CR, McKenzie $B C$, Hashim $A B$, Harris RC, Zanuzdana A, Agboado G et al (2013) Influenza vaccination for immunocompromised patients: summary of a systematic review and metaanalysis. Influenza Other Respir Viruses 7(Suppl 2):72-75

14. Hanitsch LG, Lobel M, Mieves JF, Bauer S, Babel $\mathrm{N}$, Schweiger B et al (2016) Cellular and humoral influenza-specific immune response upon vaccination in patients with common variable immunodeficiency and unclassified antibody deficiency. Vaccine 34(21):2417-2423

15. Chertow DS, Memoli MJ (2013) Bacterial coinfection in influenza: a grand rounds review. JAMA 309(3):275-282

16. de Beaucoudrey L, Samarina A, Bustamante J, Cobat A, Boisson-Dupuis S, Feinberg J et al (2010) Revisiting human IL-12Rbeta1 deficiency: a survey of 141 patients from 30 countries. Medicine (Baltimore) 89(6):381-402

17. Hambleton $S$, Goodbourn S, Young DF, Dickinson P, Mohamad SM, Valappil M et al (2013) STAT2 deficiency and susceptibility to viral illness in humans. Proc Natl Acad Sci U S A 110(8):30533058

18. Toubiana J, Okada S, Hiller J, Oleastro M, Lagos Gomez M, Aldave Becerra JC et al (2016) Heterozygous STAT1 gain-of-function mutations underlie an unexpectedly broad clinical phenotype. Blood 127(25):3154-3164

19. Picard $C$, von Bernuth $H$, Ghandil $P$, Chrabieh M, Levy O, Arkwright PD et al (2010) Clinical features and outcome of patients with IRAK-4 and MyD88 deficiency. Medicine (Baltimore) 89(6):403-425

20. McKelvie B, Top K, McCusker C, Letenyi D, Issekutz TB, Issekutz AC (2014) Fatal pneumococcal meningitis in a 7-year-old girl with interleukin-1 receptor activated kinase deficiency (IRAK-4) despite prophylactic antibiotic and IgG responses to Streptococcus pneumoniae vaccines. J Clin Immunol 34(3):267-271

21. Walter ND, Taylor TH, Shay DK, Thompson WW, Brammer L, Dowell SF et al (2010) Influenza circulation and the burden of invasive pneumococcal pneumonia during a non-pandemic period in the United States. Clin Infect Dis 50(2):175-183

22. Baxter R, Keshavan P, Welsch JA, Han L, Smolenov I (2016) Persistence of the immune response after MenACWY-CRM vaccination and response to a booster dose, in adolescents, children and infants. Hum Vaccine Immunother 12(5):1300 1310

23. Ghannam A, Pernollet M, Fauquert JL, Monnier N, Ponard D, Villiers MB et al (2008) Human C3 deficiency associated with impairments in dendritic cell differentiation, memory B cells, and regulatory T cells. J Immunol 181(7):5158-5166

24. Arbore G, West EE, Spolski R, Robertson AAB, Klos A, Rheinheimer C et al (2016) T helper 1 immunity requires complement-driven NLRP3 inflammasome activity in CD4(+) T cells. Science 352(6292):aad1210

25. Block SL, Yogev R, Hayden FG, Ambrose CS, Zeng W, Walker RE (2008) Shedding and immunogenicity of live attenuated influenza vaccine virus in subjects 5-49 years of age. Vaccine 26(38):49404946

26. Salzman MB, Sharrar RG, Steinberg S, LaRussa $P$ (1997) Transmission of varicella-vaccine virus 
from a healthy 12-month-old child to his pregnant mother. J Pediatr 131(1 Pt 1):151-154

27. Shearer WT, Fleisher TA, Buckley RH, Ballas Z, Ballow M, Blaese RM (2014) Recommendations for live viral and bacterial vaccines in immunodeficient patients and their close contacts. J Allergy Clin Immunol 133(4):961-966

28. Wiedermann U, Sitte H, al Burgmann H (2016) Impfungen bei Immundefekten/Immunsuppression - Expertenstatus und Empfehlungen. Klin Wochenschr 128(Suppl 4):337-376

29. Gelderblom WC, Cawood ME, Snyman SD, Vleggaar R, Marasas WF (1993) Structure-activity relationships of fumonisins in short-term carcinogenesis and cytotoxicity assays. Food Chem Toxicol 31(6):407-414

30. Titanji K, De Milito A, Cagigi A, Thorstensson R, Grutzmeier S, Atlas A et al (2006) Loss of memory $B$ cells impairs maintenance of long-term serologic memory during HIV-1 infection. Blood 108(5):1580-1587

31. Kim ES, Ackermann C, Toth I, Dierks P, Eberhard JM, Wroblewski R et al (2017) Down-regulation of CD73 on B cells of patients with viremic HIV correlates with B cell activation and disease progression. J Leukoc Biol 101(5):1263-1271

32. Hu Z, Luo Z, Wan Z, Wu H, Li W, Zhang T et al (2015) HIV-associated memory B cell perturbations. Vaccine 33(22):2524-2529

33. From the Centers for Disease Control and Prevention (1993) 1993 revised classification system for HIV infection and expanded surveillance case definition for AIDS among adolescents and adults. JAMA 269(6):729-730

34. Glesby MJ (1998) Immunizations during HIV infection. Curr Opin Infect Dis 11(1):17-21

35. Modjarrad K, Vermund SH (2010) Effect of treating co-infections on HIV-1 viral load: a systematic review. Lancet Infect Dis 10(7):455-463

36. Crum-Cianflone NF, Wallace MR (2014) Vaccination in HIV-infected adults. Aids Patient Care Stds 28(8):397-410

37. Association $\mathrm{CsH}$ (2015) Immunization guideines of HIV infected children. https://www.chiva.org. uk/guidelines/immunisation/. Zugegriffen: 19. Juni 2018

38. Menson EN, Mellado MJ, Bamford A, Castelli G, Duiculescu D, Marczynska M et al (2012) Guidance on vaccination of HIV-infected children in Europe. HIV Med 13(6):333-336, e1-14

39. Revised surveillance case definition for HIV infection-United States, 2014. MMWR Recommendations and reports : Morbidity and mortality weekly report Recommendations and reports. 2014;63(Rr-03):1-10

40. Laserson KF, Nyakundi D, Feikin DR, Nyambane G, Cook E, Oyieko J et al (2012) Safety of the pentavalent rotavirus vaccine (PRV), RotaTeq((R)), in Kenya, including among HIV-infected and HIVexposed infants. Vaccine 30(Suppl 1):A61-A70

41. Levin MJ, Lindsey JC, Kaplan SS, Schimana W, Lawrence J, McNeal MM et al (2017) Safety and immunogenicity of a live attenuated pentavalent rotavirus vaccine in HIV-exposed infants with or without HIV infection in Africa. AIDS 31(1):49-59

42. Bekker V, Scherpbier H, Pajkrt D, Jurriaans $S$, Zaaijer H, Kuijpers TW (2006) Persistent humoral immune defect in highly active antiretroviral therapy-treated children with HIV-1 infection: loss of specific antibodies against attenuated vaccine strains and natural viral infection. Pediatrics 118(2):e315-e322
43. Ghosh S, Feyen O, Jebran AF, Huck K, JetzekZader M, Bas M et al (2009) Memory B cell function in HIV-infected children-decreased memory $B$ cells despite ART. Pediatr Res 66(2):185-190

44. Geretti AM, Brook G, Cameron C, Chadwick D, French N, Heyderman R et al (2016) British HIV Association Guidelines on the Use of Vaccines in HIV-Positive Adults 2015. HIV Med 17(Suppl 3):S2-S81

45. Abzug MJ, Song LY, Fenton T, Nachman SA, Levin MJ, Rosenblatt HM (2007) Pertussis booster vaccination in HIV-infected children receiving highly active antiretroviral therapy. Pediatrics 120(5):e1190-e1202

46. Robert Koch-Institut (2018) Empfehlungen der Ständigen Impfkommission (STIKO) am RKI 2018/2019. Epidemiologisches Bulletin, 34/2018

47. Ida S, Tachikawa N, Nakajima A, Daikoku M, Yano M, Kikuchi Y et al (2002) Influence of human immunodeficiency virus type 1 infection on acute hepatitis A virus infection. Clin Infect Dis 34(3):379-385

48. Kourkounti S, Papaizos V, Leuow K, Kordosis T, Antoniou C (2013) Hepatitis A vaccination and immunological parameters in HIV-infected patients. Viral Immunol 26(5):357-363

49. Mena G, Garcia-Basteiro AL, Bayas JM (2015) Hepatitis B and A vaccination in HIV-infected adults: A review. Hum Vaccin Immunother 11(11):2582-2598

50. Kourkounti S, Mavrianou N, Paparizos VA, Kyriakis K, Hatzivassiliou M, Kordosis T et al (2012) Immune response to hepatitis $A$ vaccination in HIV-infected men in Greece. Int J Std Aids 23(7):464-467

51. Tseng YT, Chang SY, Liu WC, Sun HY, Wu CH, Wu PY et al (2013) Comparative effectiveness of two doses versus three doses of hepatitis $A$ vaccine in human immunodeficiency virus-infected and -uninfected men who have sex with men. Hepatology 57(5):1734-1741

52. Kerneis S, Desaint C, Brichler S, Rey D, Belarbi L, Gordien E et al (2011) Long-term persistence of humoral immunity after hepatitis $A$ vaccination in HIV-infected adults. J Acquir Immune Defic Syndr 57(3):e63-6

53. Launay O, Grabar S, Gordien E, Desaint C, Jegou $D$, Abad S et al (2008) Immunological efficacy of a three-dose schedule of hepatitis A vaccine in HIV-infected adults: HEPAVAC study. J Acquir Immune Defic Syndr 49(3):272-275

54. Lin KL et al (2017) Effectiveness of HAV vaccination among HIV-positive patients during an acute hepatitis A outbreak. Conference on Retroviruses and Opportunistic Infections (CROI), Seattle, S abstract 582

55. Jablonowska E, Kuydowicz J (2014) Durability of response to vaccination against viral hepatitis $A$ in HIV-infected patients: a 5-year observation. Int J Std Aids 25(10):745-750

56. Robert Koch-Institut (2015) RKI-Ratgeber Hepatitis A. http://www.rki.de/DE/Content/Infekt/ EpidBull/Merkblaetter/Ratgeber_HepatitisA. html\#doc2374552bodyText14. Zugegriffen: 19. Juni 2018

57. Robert Koch-Institut (2013) Ständige Impfkommission am RKl:Wissenschaftliche Begründung für die Änderung der Empfehlung zur Impfung gegen Hepatitis B. Epidemiologisches Bulletin 36/37 2013

58. van den Berg $R$, van Hoogstraten I, van Agtmael M (2009) Non-responsiveness to hepatitis B vaccination in HIV seropositive patients; possible causes and solutions. AIDS Rev 11(3):157-164

59. Catherine FX, Piroth $L$ (2017) Hepatitis B virus vaccination in HIV-infected people: a review. Hum Vaccin Immunother 13(6):1-10

60. de Silva TI, Green ST, Cole J, Stone BJ, Dockrell $D H$, Vedio AB (2014) Successful use of Fendrix in HIV-infected non-responders to standard hepatitis B vaccines. J Infect 68(4):397-399

61. Alon D, Stein GY, Hadas-Golan V, Tau L, Brosh T, Turner D (2017) Immunogenicity of sci-B-Vac (a third-generation hepatitis B vaccine) in HIVpositive adults. Isr Med Assoc J 19(3):143-146

62. Roggendorf H (2015) Non-Responder nach Hepatitis B-Impfung: Problemlösung ist in Reichweite. Dtsch Arztebl 112/2015:C1281

63. Shouval D, Roggendorf H, Roggendorf M (2015) Enhanced immune response to hepatitis $B$ vaccination through immunization with a PreS1/Pre-S2/S vaccine. Med Microbiol Immunol 204(1):57-68

64. Giacomet $V$ et al (2017) Immunological responses after a booster dose of HBV vaccine in HIV-infected youth. Conference on Retroviruses and Opportunistic Infections (CROI), Seattle, S abstract. 2017

65. Flynn PM, Cunningham CK, Rudy B, Wilson CM, Kapogiannis B, Worrell C et al (2011) Hepatitis B vaccination in HIV-infected youth: a randomized trial of three regimens. J Acquir Immune Defic Syndr 56(4):325-332

66. Bakker M, Bunge EM, Marano C, de Ridder M, De Moerlooze $L$ (2016) Immunogenicity, effectiveness and safety of combined hepatitis $A$ and $B$ vaccine: a systematic literature review. Expert Rev Vaccines 15(7):829-851

67. Cunningham AL, Lal H, Kovac M, Chlibek R, Hwang SJ, Diez-Domingo J et al (2016) Efficacy of the Herpes Zoster Subunit Vaccine in Adults 70 Years of Age or Older. N Engl J Med 375(11):1019-1032

68. Lal H, Cunningham AL, Godeaux O, Chlibek R, Diez-Domingo J, Hwang SJ et al (2015) Efficacy of an adjuvanted herpes zoster subunit vaccine in older adults. N Engl J Med 372(22):2087-2096

69. Berkowitz EM, Moyle G, Stellbrink HJ, Schurmann D, Kegg S, Stoll M et al (2015) Safety and immunogenicity of an adjuvanted herpes zoster subunit candidate vaccine in HIV-infected adults: a phase $1 / 2$ a randomized, placebo-controlled study. J Infect Dis 211(8):1279-1287

70. Siedler A, Koch J, Ultsch B et al (2017) Background paper to the decision not to recommend a standard vaccination with the live attenuated herpes zoster vaccine for the elderly in Germany. Statement of the German Standing Committee on Vaccination (STIKO) at the Robert Koch Institute (RKI). Bundesgesundheitsblatt 60:1162-1179

71. Konopnicki D, Manigart Y, Gilles C, Barlow P, De Marchin J, Feoli F et al (2016) High-risk human papillomavirus genotypes distribution in a cohort of HIV-positive women living in Europe: epidemiological implication for vaccination against human papillomavirus. AIDS 30(3):425-433

72. Patel P, Bush T, Conley L et al (2017) Prevalence, clearance, and incidence of human papillomavirus (HPV) types covered by current vaccines in HIV-linfected men in the SUN study. Conference on Retroviruses and Opportunistic Infections (CROI), Seattle, S abstract 597

73. Meites E, Gorbach PM, Gratzer B, Panicker G, Steinau M, Collins T et al (2016) Monitoring for 
Human Papillomavirus Vaccine Impact Among Gay, Bisexual, and Other Men Who Have Sex With Men-United States, 2012-2014. J Infect Dis 214(5):689-696

74. Kreuter A, Potthoff A, Brockmeyer NH, Gambichler T, Swoboda J, Stucker M et al (2010) Anal carcinoma in human immunodeficiency virus-positive men: results of a prospective study from Germany. Br J Dermatol 162(6):1269-1277

75. Piketty $C$, Selinger-Leneman $H$, Bouvier AM, Belot A, Mary-Krause M, Duvivier C et al (2012) Incidence of HIV-related anal cancer remains increased despite long-term combined antiretroviral treatment: results from the french hospital database on HIV. J Clin Oncol 30(35):4360-4366

76. Committee Opinion No. 704 Summary: Human Papillomavirus Vaccination. Obstet Gynecol. 2017;129(6):1155-6.

77. Kojic EM, Kang M, Cespedes MS, Umbleja T, Godfrey C, Allen RT et al (2014) Immunogenicity and safety of the quadrivalent human papillomavirus vaccine in HIV-1-infected women. Clin Infect Dis 59(1):127-135

78. Lin A, Ong KJ, Hobbelen P, King E, Mesher D Edmunds WJ et al (2017) Impact and costeffectiveness of selective human papillomavirus vaccination of men who have sex with men. Clin Infect Dis 64(5):580-588

79. Wilkin T, Lee JY, Lensing SY, Stier EA, Goldstone SE, Berry JM et al (2010) Safety and immunogenicity of the quadrivalent human papillomavirus vaccine in HIV-1-infected men. J Infect Dis 202(8):1246-1253

80. Joura EA, Giuliano AR, Iversen OE, Bouchard C, Mao C, Mehlsen J et al (2015) A 9-valent HPV vaccine against infection and intraepithelial neoplasia in women. N Engl J Med 372(8):711723

81. Palefsky JM, Giuliano AR, Goldstone S, Moreira ED Jr., Aranda C, Jessen H et al (2011) HPV vaccine against anal HPV infection and anal intraepithelial neoplasia. N Engl J Med 365(17):1576-1585

82. AG Influenza der Ständigen Impfkommission (STIKO) (2018) Wissenschaftliche Begründung für die Empfehlung des quadrivalenten saisonalen Influenza-impfstoffs. Epid Bull 2:19-28 https://doi.org/10.17886/EpiBull-2018-002

83. Remschmidt C, Wichmann O, Harder T (2014) Influenza vaccination in HIV-infected individuals: systematic review and assessment of quality of evidence related to vaccine efficacy, effectiveness and safety. Vaccine 32(43):5585-5592

84. Lau YF, Tang LH, Chien Lye D, Ooi EE, Leo YS (2017) Serological response to trivalent inactivated influenza vaccine in HIV-infected adults in Singapore. Hum Vaccin Immunother 13(3):551-560

85. Simmons RD, Kirwan P, Beebeejaun K, Riordan A, Borrow R, Ramsay ME et al (2015) Risk of invasive meningococcal disease in children and adults with HIV in England: a population-based cohort study. BMC Med 13:297

86. Miller L, Arakaki L, Ramautar A, Bodach S, Braunstein SL, Kennedy J et al (2014) Elevated risk for invasive meningococcal disease among persons with HIV. Ann Intern Med 160(1):30-37

87. Cohen C, Singh E, Wu HM, Martin S, de Gouveia L, Klugman KP et al (2010) Increased incidence of meningococcal disease in HIV-infected individuals associated with higher case-fatality ratios in South Africa. AIDS 24(9):1351-1360
88. Blackwell CW (2017) Meningococcal vaccination in men who have sex with men. Public Health Nurs 34(2):147-151

89. Hellenbrand W, Claus H, Schink S, Marcus U, Wichmann O, Vogel U (2016) Risk of invasive meningococcal disease in men who have sex with men: lessons learned from an outbreak in Germany, 2012-2013. PLoS ONE 11(8):e160126

90. Folaranmi TA, Kretz CB, Kamiya H, MacNeil JR, Whaley MJ, Blain A et al (2017) Increased risk for meningococcal disease among men who have sex with men in the United States, 2012-2015. Clin Infect Dis 65(5):756-763

91. Dubois $C$, Liegeon AL, Fabbro C, Truchetet $F$ (2017) Neisseria meningitidis urethritis: two case reports. Ann Dermatol Venereol 144(10):621623

92. Gutierrez-Fernandez J, Medina V, HidalgoTenorio C, Abad R (2017) Two cases of Neisseria meningitidis proctitis in HIV-positive men who have sex with men. Emerging Infect Dis 23(3):542-543

93. Siberry GK, Warshaw MG, Williams PL, Spector SA, Decker MD, Jean-Philippe P et al (2012) Safety and immunogenicity of quadrivalent meningococcal conjugate vaccine in 2- to 10-yearold human immunodeficiency virus-infected children. Pediatr Infect Dis J 31(1):47-52

94. Lujan-Zilbermann J, Warshaw MG, Williams PL, Spector SA, Decker MD, Abzug MJ et al (2012) Immunogenicity and safety of 1 vs 2 doses of quadrivalent meningococcal conjugate vaccine in youth infected with human immunodeficiency virus. J Pediatr 161(4):676-681.e2

95. Warshaw MG, Siberry GK, Williams P, Decker MD Jean-Philippe P, Lujan-Zilbermann J (2017) Immunogenicity of a booster dose of quadrivalent meningococcal conjugate vaccine in previously immunized HIV-infected children and youth. J Pediatric Infect Dis Soc 6(3):e69-e74

96. Yin Z, Rice BD, Waight $\mathrm{P}$, Miller E, George $\mathrm{R}$, Brown AE et al (2012) Invasive pneumococcal disease among HIV-positive individuals, 2000-2009. AIDS 26(1):87-94

97. Jallow S, Madhi SA (2017) Pneumococcal conjugate vaccine in HIV-infected and HIV-exposed, uninfected children. Expert Rev Vaccines 16(5):453-465

98. Nunes $M C$, von Gottberg $A$, de Gouveia $L$, Cohen C, Moore DP, Klugman KP et al (2011) The impact of antiretroviral treatment on the burden of invasive pneumococcal disease in South African children: a time series analysis. AIDS 25(4):453-462

99. von Mollendorf C, von Gottberg A, Tempia S, Meiring S, de Gouveia L, Quan V et al (2015) Increased risk for and mortality from invasive pneumococcal disease in HIV-exposed but uninfected infants aged $<1$ year in South Africa, 2009-2013. Clin Infect Dis 60(9):1346-1356

100. Lesourd A, Leporrier J, Delbos V, Unal G, Honore P, Etienne M et al (2016) Antiretroviral Therapy as Prevention of ... Pneumococcal Infections? Open Forum Infect Dis 3(4):ofw228

101. Feldman C, Anderson R, Rossouw T (2017) HIV-related pneumococcal disease prevention in adults. Expert Rev Respir Med 11(3):181-199

102. French N, Gordon SB, Mwalukomo T, White SA, Mwafulirwa G, Longwe $\mathrm{H}$ et al (2010) A trial of a 7-valent pneumococcal conjugate vaccine in HIV-infected adults. N Engl J Med 362(9):812822
103. Penaranda $M$, Falco V, Payeras $A$, Jordano $Q$, Curran A, Pareja A et al (2007) Effectiveness of polysaccharide pneumococcal vaccine in HIV-infected patients: a case-control study. Clin Infect Dis 45(7):e82-7

104. Teshale EH, Hanson D, Flannery B, Phares C, Wolfe M, Schuchat A et al (2008) Effectiveness of 23-valent polysaccharide pneumococcal vaccine on pneumonia in HIV-infected adults in the United States, 1998-2003. Vaccine 26(46):58305834

105. lyer AS, Leggat DJ, Ohtola JA, Duggan JM, Georgescu CA, Al Rizaiza AA et al (2015) Response to Pneumococcal Polysaccharide Vaccination in HIV-Positive Individuals on Long Term Highly Active Antiretroviral Therapy. J AIDS Clin Res. https://doi.org/10.4172/2155-6113.1000419

106. Leggat $D J$, lyer AS, Ohtola JA, Kommoori S, Duggan JM, Georgescu CA et al (2015) Response to pneumococcal polysaccharide vaccination in newly diagnosed HIV-positive individuals. J AIDS Clin Res. https://doi.org/10.4172/21556113.1000419

107. Levin MJ, Song LY, Fenton T, Nachman S, Patterson J, Walker R et al (2008) Shedding of live vaccine virus, comparative safety, and influenzaspecific antibody responses after administration of live attenuated and inactivated trivalent influenza vaccines to HIV-infected children. Vaccine 26(33):4210-4217

108. Kim DK, Riley LE, Harriman $\mathrm{KH}$, Hunter P, Bridges $C B$ (2017) Advisory committee on immunization practices recommended immunization schedule for adults aged 19 years or older-United States, 2017. Mmwr Morb Mortal Wkly Rep 66(5):136138

109. Robert Koch-Institut (2017) Stellungnahme der Ständigen Impfkommission (STIKO) am RKI: Fachliche Anwendungshinweise zur MasernPostexpositionsprophylaxe bei Risikopersonen. Epidemiol Bull 2/2017:17-25

110. Taweesith W, Puthanakit T, Kowitdamrong $E_{\text {, }}$ Bunupuradah T, Wongngam W, Phasomsap C et al (2011) The immunogenicity and safety of live attenuated varicella-zoster virus vaccine in human immunodeficiency virus-infected children. Pediatr Infect Dis J 30(4):320-324

111. Weinberg A, Levin MJ, Macgregor RR (2010) Safety and immunogenicity of a live attenuated varicella vaccine in VZV-seropositive HIVinfected adults. Hum Vaccin 6(4):318-321

112. Robert Koch-Institut (2013) Mitteilung der Ständigen Impfkommission (STIKO) am RKI. Empfehlung und wissenschaftliche Begründung der Empfehlung zur Rotavirus-Standardimpfung von Säuglingen. Epidemiologisches Bulletin, 35/2013

113. Lewis DJ, Gilks CF, Ojoo S, Castello-Branco LR, Dougan G, Evans MR et al (1994) Immune response following oral administration of cholera toxin B subunit to HIV-1-infected UK and Kenyan subjects. AIDS 8(6):779-785

114. Westrop SJ, Moyle G, Jackson A, Nelson M, Mandalia S, Imami N (2012) CCR5 antagonism impacts vaccination response and immune profile in HIV-1 infection. Mol Med 18:1240-1248

115. Robert Koch-Institut (2017) FSME: Risikogebiete in Deutschland (Stand: April 2017). Epidemiologisches Bulletin. http://www.rki.de/DE/Content/ Infekt/EpidBull/Archiv/2017/17/Art_01.html. Zugegriffen: 19. Juni 2018

116. Pfizer. Fachinformation FSME-Immun für Erwachsene. 2017. 
117. GSK. Fachinformation Encepur Erwachsene. 2017.

118. Barte $\mathrm{H}$, Horvath TH, Rutherford GW (2014) Yellow fever vaccine for patients with HIV infection. Cochrane Database Syst Rev. https:// doi.org/10.1002/14651858.CD010929.pub2

119. Kengsakul K, Sathirapongsasuti K, Punyagupta $S$ (2002) Fatal myeloencephalitis following yellow fever vaccination in a case with HIV infection. J Med Assoc Thai 85(1):131-134

120. Avelino-Silva VI, Miyaji KT, Hunt PW, Huang Y, Simoes M, Lima SB et al (2016) CD4/CD8 ratio and $\mathrm{KT}$ ratio predict yellow fever vaccine Immunogenicity in HIV-infected patients. Plos Negl Trop Dis 10(12): 55219

121. Veit O, Niedrig M, Chapuis-Taillard C, Cavassini M, Mossdorf E, Schmid P et al (2009) Immunogenicity and safety of yellow fever vaccination for 102 HIV-infected patients. Clin Infect Dis 48(5):659-666

122. Veit $O$, Domingo $C$, Niedrig $M$, Staehelin C, Sonderegger B, Delphine H et al (2017) Long-term immune response to yellow fever vaccination in HIV-infected individuals depends on HIV-RNA suppression status: Implications for vaccination schedule. Clin Infect Dis. https:// doi.org/10.1093/cid/cix960

123. Deutsche Tropenmedizinische Gesellschaft, DTG (2017) Reisemedizinische Empfehlungen. http:// dtg.org/empfehlungen-und-leitlinien/empfehlungen/impfungen.html. Zugegriffen: 19. Juni 2018

124. Rojanasuphot S, Shaffer N, Chotpitayasunondh T, Phumiamorn S, Mock P, Chearskul S et al (1998) Response to JE vaccine among HIVinfected children, Bangkok, Thailand. Southeast Asian J Trop Med Public Health 29(3):443-450

125. Pancharoen C, Thisyakorn U, Tantawichien T, Jaijaroensup W, Khawplod P, Wilde H (2001) Failure of pre- and postexposure rabies vaccinations in a child infected with HIV. Scand J Infect Dis 33(5):390-391

126. Ni JD, Xiong YZ, Wang XJ, Xiu LC (2013) Does increased hepatitis $B$ vaccination dose lead to a better immune response in HIV-infected patients than standard dose vaccination: a metaanalysis? Int J Std Aids 24(2):117-122

127. MacNeil JR, Rubin LG, Patton M, Ortega-Sanchez IR, Martin SW (2016) Recommendations for use of meningococcal conjugate vaccines in HIV-infected persons_-advisory committee on immunization practices, 2016. MMWR Morb Mortal Wkly Rep 65(43):1189-1194

128. Slayter KL, Singer J, Lee TC, Kayhty H, Schlech WF (2013) Immunization against pneumococcal disease in HIV-infected patients: conjugate versus polysaccharide vaccine before or after reconstitution of the immune system (CTN-147). Int J Std Aids 24(3):227-231

129. Sogaard OS, Schonheyder HC, Bukh AR, Harboe ZB, Rasmussen TA, Ostergaard L et al (2010) Pneumococcal conjugate vaccination in persons with HIV: the effect of highly active antiretroviral therapy. AIDS 24(9):1315-1322

130. Stermole BM, Grandits GA, Roediger MP, Clark BM, Ganesan A, Weintrob AC et al (2011) Longterm safety and serologic response to measles, mumps, and rubella vaccination in HIV-1 infected adults. Vaccine 29(16):2874-2880

131. Schwarze-Zander C, Draenert R, Lehmann C, Stecher M, Boesecke C, Sammet S et al (2017) Measles, mumps, rubella and VZV: importance of serological testing of vaccine-preventable diseases in young adults living with HIV in Germany. Epidemiol Infect 145(2):236-244 